\title{
Country-resolved combined emission and socio-economic pathways based on the Representative Concentration Pathway (RCP) and Shared Socio-Economic Pathway (SSP) scenarios
}

\author{
Johannes Gütschow $^{1}$, M. Louise Jeffery ${ }^{1,3}$, Annika Günther ${ }^{1}$, and Malte Meinshausen ${ }^{2}$ \\ ${ }^{1}$ Potsdam Institute for Climate Impact Research, Telegrafenberg, Potsdam, Germany \\ ${ }^{2}$ Climate \& Energy College, School of Earth Sciences, The University of Melbourne, Melbourne, Australia \\ ${ }^{3}$ NewClimate Institute, Berlin, Germany \\ Correspondence: Johannes Gütschow (johannes.guetschow@ pik-potsdam.de)
}

Received: 22 April 2020 - Discussion started: 4 June 2020

Revised: 28 January 2021 - Accepted: 31 January 2021 - Published: 11 March 2021

\begin{abstract}
Climate policy analysis needs reference scenarios to assess emission targets and current trends. When presenting their national climate policies, countries often showcase their target trajectories against fictitious socalled baselines. These counterfactual scenarios are meant to present future greenhouse gas (GHG) emissions in the absence of climate policy. These so-called baselines presented by countries are often of limited use, as they can be exaggerated and as the methodology used to derive them is usually not transparent. Scenarios created by independent modeling groups using integrated assessment models (IAMs) can provide different interpretations of several socio-economic storylines and can provide a more realistic backdrop against which the projected target emission trajectory can be assessed. However, the IAMs are limited in regional resolution. This resolution is further reduced in intercomparison studies, as data for a common set of regions are produced by aggregating the underlying smaller regions. Thus, the data are not readily available for country-specific policy analysis. This gap is closed by downscaling regional IAM scenarios to the country level. The last of such efforts has been performed for the SRES ("Special Report on Emissions Scenarios") scenarios, which are over a decade old by now. CMIP6 (Coupled Model Intercomparison Project phase 6) scenarios have been downscaled to a grid; however they cover only a few combinations of forcing levels and SSP storylines with only a single model per combination. Here, we provide up-to-date country scenarios, downscaled from the full RCP (Representative Concentration Pathway) and SSP (Shared Socio-Economic Pathway) scenario databases, using results from the SSP GDP (gross domestic product) country model results as drivers for the downscaling process. The data are available at https://doi.org/10.5281/zenodo.3638137 (Gütschow et al., 2020).
\end{abstract}

1

In order to coordinate climate change research, different sets of joint scenarios have been developed. For example, the Intergovernmental Panel on Climate Change (IPCC) "Special Report on Emissions Scenarios" (SRES) summarized available literature and provided six illustrative marker scenarios of emissions as well as socio-economic storylines to enable cross-comparison of a wide range of mitigation, adaptation, and climate change impact studies (Nakicenovic and Swart, 2000; Riahi et al., 2007). These "marker scenarios are no more or less likely than any other scenarios but are considered by the SRES writing team as illustrative of a particular storyline" (Nakicenovic et al., 2000). More recently a new 
scenario process was started (Moss et al., 2010). The emission scenarios used in that process are the Representative Concentration Pathways (RCPs) that have been developed on the basis of four harmonized emission scenarios from different integrated assessment model (IAM) modeling groups (van Vuuren et al., 2011a; Meinshausen et al., 2011; van Vuuren et al., 2011b; Thomson et al., 2011; Masui et al., 2011; Riahi et al., 2011).

In a second step following the selection of concentrationemission scenarios, five different socio-economic storylines were developed, the Shared Socio-Economic Pathways (SSPs; Nakicenovic et al., 2014), allowing for mitigation and impact researchers to combine low- and high-emission futures with different assumptions about socio-economic development in terms of population, gross domestic product (GDP), and further indicators (van Vuuren et al., 2014). This is an advancement over the SRES scenarios, as in the SRES scenarios, an emission future was often assumed to be in line with a single socio-economic development only. The exception during the SRES scenario process was the A1 scenario family that was during the plenary adoption process split out into three sub-scenarios, A1FI, A1T, and A1B, indicating the importance of socio-economic assumptions below the high-level "high-growth" storyline of the A1 family and their respective effect on emissions. The new SSP socioeconomic storylines were modeled by several independent groups to quantify them in terms of GDP (Leimbach et al., 2017; Dellink et al., 2017; Crespo Cuaresma, 2017), population (KC and Lutz, 2017), and urbanization (Jiang and O'Neill, 2017) development on a country or detailed regional level. These scenario quantifications are called the SSP basic elements.

As a further step in this process, several research groups used IAMs to simulate combinations of the Shared Socio-Economic Pathways with Representative Concentration Pathway forcing targets (Riahi et al., 2017; Kriegler et al., 2017; Fujimori et al., 2017; Calvin et al., 2017; Fricko et al., 2017; van Vuuren et al., 2017; Rogelj et al., 2018).

While the IAMs internally use between 11 and 26 regions, the published data are limited to a set of macro regions, namely the RC5 regions (RC: region categorization; see Appendix II.2.2 of Edenhofer et al., 2014) for the RCPs and the RC5.2 regions (IIASA, 2016) for the SSPs. The reasons for this limitation are manifold: decisions of the intercomparison protocols allowing for a wide participation of modeling groups lead to a neglect of some regional detail, but more fundamentally, the quality of calibration and input data for the global modeling exercises that produced the SSP GDP and population projections degrades on finer scales and hence limits the projection models. Furthermore, so far there are no official and comprehensive emission inventories for most countries that are categorized as non-Annex I countries, as their reporting requirements under the UNFCCC (United Nations Framework Convention on Climate Change) have been very limited compared to those categorized as Annex I (industrialized) countries.

This limitation of country-level detail can severely hamper a number of studies: climate impact assessments, quantification of equity principles for effort sharing of mitigation, or the assessment of pledges of countries against benchmark reference and mitigation scenarios. The required long-term country-level scenarios are only available based on the SRES scenarios that are now over a decade old (van Vuuren et al., 2007; Höhne et al., 2010).

Sector and gas resolution is limited as well. While the RCP scenarios have detailed sectoral data for some gases (e.g., $\mathrm{CH}_{4}$ ), the resolution of $\mathrm{CO}_{2}$ is limited to separating land use emissions from the fossil fuel and industrial emissions in the publicly available database. The shared SSPv2 IAM outputs only resolve between land use and fossil fuel and industrial emissions, and hence also coarse disaggregation is harmonized towards common historical emission levels. The RCPs resolve individual fluorinated gases, while the SSPv2 database only provides data for aggregated fluorinated gases.

Recently, the scenarios for the Coupled Model Intercomparison Project phase 6 (CMIP6; World Climate Research Programme, 2019) have been released so that they are also based on the RCP forcing levels and SSP storylines. They provide socio-economic and emission data on a more detailed regional, gas, and categorical level. Even though data exist that are downscaled to a grid - with an intermediate step of downscaling to the country level (Gidden et al., 2019) there are no country-resolved data available. Transformation of gridded data to the country level is problematic for small countries unless the grid is very fine. Furthermore, only a few combinations of RCP forcings with SSP storylines each from a single model only are included in the SSP CMIP6 database (IIASA, 2018; Gidden et al., 2019; Feng et al., 2020).

To fill this gap and provide country-level data for all RCPSSP combinations and IAMs, we downscale the RCPs and SSPv2 emission scenarios to the country level using the SSPbasic-elements socio-economic country-level data. To downscale the RCPs we use per country GDP results from all three groups provided in SSP-basic-elements GDP scenarios. Our data thus enable a comparison of results between SSP-basicelements modeling groups and IAMs and provide ranges for future country emissions under different SSP storylines and $\mathrm{RCP}$ forcing targets instead of the seeming certainty given by the single model used in the SSP CMIP6 data.

Historical emission data are taken from the PRIMAP-hist v2.1 (Potsdam Real-time Integrated Model for the probabilistic Assessment of emission Paths) source, which provides data for all countries and Kyoto greenhouse gases (Kyoto GHGs) (Gütschow et al., 2016, 2019) based on official UNFCCC data complemented by third-party data to fill the reporting gaps for non-Annex I countries and years before 1990. Historical socio-economic data are taken from Gütschow (2019), which is based on UN population data 
(UN DESA/Population Division, 2019) and the Maddison Project database (Bolt et al., 2018a, b) as well as other sources to fill missing values. Our downscaling methodology is based on existing approaches, which we extend and improve to enable its use on scenarios with negative emissions.

The paper is structured as follows: we begin with the review of existing downscaling methodologies and the introduction of our methodology in Sect. 2. In the following Sect. 3 we describe the data sources this work is based on and how they are processed. Section 4 presents a detailed stepby-step description of our downscaling approach. Results are presented in Sect. 5, followed by a discussion of limitations (Sect. 6) and conclusions (Sect. 8). The availability of the resulting datasets is described in Sect. 7. The Appendix gives details on the data sources for the historical socio-economic data, data coverage of the different scenarios, and additional methodological details. The Appendix also provides tables with acronyms and definitions used throughout this paper.

\section{Methods}

\subsection{Notation}

In the following we consistently assume data are given for a region $\mathbb{R}$, which we describe as a set of countries $\mathcal{C} \in \mathbb{R}$. We denote this by subscript identifiers. A regional emission pathway is denoted by $E_{\mathbb{R}}$; an emission pathway for a specific country $\mathcal{C}$ is denoted by $E_{\mathcal{C}}$. Emissions for a specific year $y$ are denoted by $E_{\mathbb{R}}(y)$ or $E_{\mathcal{C}}(y)$ respectively. We denote emission intensity by EI, GDP by GDP, and population by POP in a similar way. For calculations with full pathways we assume that the same operation is applied on data points for all years individually; i.e., EI - GDP denotes the multiplication of emission intensity by GDP for each year. EI - GDP $(y)$ denotes the multiplication of the whole emission intensity time series by the GDP of year $y$. Emissions and emission intensities are defined for several variables (gases and pollutants), but as we are only working on one gas at a time, we do not introduce another subscript index for these variables for the sake of a simpler notation. The method could as well be used to downscale the world to the regional level or country emissions to the state level. We only consider downscaling from larger to smaller economic or political regions, e.g., from the region level to the country level, and do not consider spatial downscaling of data from coarser to finer grids. However, if, e.g., GDP data are given on a finer grid than emission data, the method described here could also be applied.

We denote the RCP scenarios and forcing levels as RCP and the downscaled RCP scenarios as RCPd. The SSP basic elements are abbreviated as SSPbe. With SSPv2 we denote the SSP IAM scenarios version 2, and with SSPv2d we denote the downscaled SSPv2 scenarios. When using just SSP we refer to the SSP storylines; e.g., RCP-SSP refers to the combination of RCP forcing levels with SSP storylines.

\subsection{Existing downscaling methods}

Several methods to downscale emission data are found in the literature. Which methods can be used depends on available data and the choice between a simple and transparent method versus a more realistic but also more complex approach. Common to all methods is the need for an auxiliary dataset called the downscaling key. Data from the downscaling key are used directly or as the basis for a model to split the regional data to the country level. It could be data for the same variable from a different source or for a different variable with some known or assumed correlation to the variable that is to be downscaled. The data can either cover the same period of time, historical years only, or even a single year only. The basis of our work is the three groups of methods identified in van Vuuren et al. (2007), which differ in their use of the downscaling key. They specifically consider cases where country-resolved emission data are available up to a certain year but future projections are only available for larger regions, as this is the situation given by the combination of RCP scenarios with the SSP-basic-elements and the SSPv2 IAM runs.

- Linear downscaling. This is the simplest method. The downscaling key is a dataset for the same variable as the to-be-downscaled data, e.g., both $\mathrm{CO}_{2}$ emissions. Historical emission data for one single year $y_{0}$ (or an averaged period) is used to define shares $S_{\mathcal{C}}\left(y_{0}\right)=$ $E_{\mathcal{C}}\left(y_{0}\right) / E_{\mathbb{R}}\left(y_{0}\right)$ for each country $\mathcal{C} \in \mathbb{R}$. These shares $S_{\mathcal{C}}\left(y_{0}\right)$ are used to distribute emissions from the regional pathway to individual countries: $E_{\mathcal{C}}=S_{\mathcal{C}}\left(y_{0}\right) E_{\mathbb{R}}$. The relative emissions of countries within a region are thus fixed at the historical level for the whole resulting scenario. This approach was used by the MATCH group (Modeling and Assessment of Contributions to Climate Change UNFCCC ad hoc group; Höhne et al., 2010) to downscale SRES scenarios from the region to country level.

While this approach is very transparent and straight forward, it has the downside that it can not model differing developments within a region. All countries in a region will have the same emission growth rates defined by the regional pathway. The method is likely to overestimate future emissions of relatively developed countries compared to those of developing countries with high economic growth within the same region. See also results Sect. 5 .

- External-input-based downscaling. In this method a country-resolved key pathway $K_{\mathcal{C}}$ for some variable is available. The shares $S_{\mathcal{C}}=K_{\mathcal{C}} / K_{\mathbb{R}}$ defined by this pathway are used to downscale the regional pathway: $E_{\mathcal{C}}=S_{\mathcal{C}} E_{\mathbb{R}}$.

This method can take different developments within the region into account but only to the extent the down- 
scaling key data $K$ does itself. The intra-regional differentiation will be that of the existing key source, only scaled with the ratio of the regional scenario pathway to the regional key pathway. If the key data for a different variable than the regional data are to be downscaled, a systematic error is introduced if the two variables are not linearly correlated. If the correlation is known, this might be compensated, but in general this will not be the case. We use this method to downscale the SSPv2 socio-economic data and the PIK (Potsdam Institute for Climate Impact Research) SSPbe data from the region to country level.

- Convergence downscaling. Convergence downscaling uses the assumption that a given variable converges among countries within a given region. The convergence assumption only makes sense for variables which are independent of the size of a country, e.g., emission intensity (emissions per unit of GDP) and GDP per capita but not absolute emissions or GDP. This method needs historical information for the target variable (e.g., emissions), and in the case that the target variable is not independent of country size an auxiliary variable that can be used to create a convergence variable which does not depend on country size (e.g., GDP to create emission intensity). Furthermore, regional and country time series for the auxiliary variable are needed for the full downscaling period.

The downscaling process begins with the creation of a temporary pathway of the convergence variable for all countries, starting from the historical values for each country and ending at a common value obtained from the given regional pathway. Thus, all countries converge to the regional value in the convergence year. The convergence year can be set depending on the scenario storyline and governs if full or partial convergence is achieved within the scenario timeframe. To accomplish partial convergence, the convergence year is set after the end of the scenario timeframe, and thus some form of extrapolation of the regional data is needed. In the case that we used an auxiliary variable we need to multiply the obtained pathways by the pathways of the auxiliary variable to obtain the temporary pathways for the downscaling variable. The obtained temporary pathways are scaled such that their sum matches the regional pathway prescribed by the scenario for every year individually.

Convergence downscaling was employed by van $\mathrm{Vu}-$ uren et al. $(2006,2007)$ to downscale the SRES scenarios from the region to country level.

This method employs socio-economic scenarios as the drivers of the downscaling process and is therefore a promising candidate to downscale the RCP and SSPv2 scenarios using the SSP-basic-elements country-level data. Details are presented in Sect. 2.3.
Figure 1 shows examples for the three methods described above.

Which method is most appropriate depends on the intended use and available data. If only historical data are available, linear downscaling is often the only method that can be used to derive country-level future emissions from regional emission projections. Convergence downscaling is a good option, if the variable that should be downscaled can be expressed relative to some known variable to make it comparable between different countries, which is a prerequisite for the convergence concept to be meaningful. If emission data are available from a different source, the external-input method is a good option.

For our task we use a slightly modified version of the convergence downscaling which can handle negative emissions and uses the GDP data provided by the SSP basic elements and the IPAT equation (described below) to downscale the emissions of the greenhouse gases included in the RCP and SSPv2 scenarios. Our method is very similar to the convergence downscaling employed in van Vuuren et al. (2006, 2007) (see Sect. 2.3).

\subsection{IPAT convergence downscaling}

In this section we present the details of our modified version of the IPAT-based convergence downscaling introduced in van Vuuren et al. (2006, 2007).

Similar to the original approach the basis for the downscaling of emissions is given by the IPAT equation (Ehrlich and Holdren, 1971; Chertow, 2000):

$I=P \cdot A \cdot T$.

The idea behind the equation is to decompose an environmental impact $I$ into its drivers. The IPAT equation assumes $I$ is linear in all three drivers: the population size $P$, the affluence $A$ as a measure of consumption of goods per capita, and a technology factor $T$ which governs the environmental impact per unit of consumed goods. In our case the environmental impacts to be described are greenhouse gas emissions. As we work on an economy-wide level the affluence is described by GDP per capita, and the emission intensity of the GDP plays the role of the technology factor. The driver behind emission growth is total GDP (as a measure of consumption and production), not the size of the population.

Our IPAT equation variant thus becomes

$E_{\mathcal{C}}=\operatorname{POP}_{\mathcal{C}} \frac{\mathrm{GDP}_{\mathcal{C}}}{\operatorname{POP}_{\mathcal{C}}} \frac{E_{\mathcal{C}}}{\operatorname{GDP}_{\mathcal{C}}}=\mathrm{GDP}_{\mathcal{C}} \cdot \mathrm{EI}_{\mathcal{C}}$,

where $\mathrm{EI}_{\mathcal{C}}=E_{\mathcal{C}} / \mathrm{GDP}_{\mathcal{C}}$ is the emission intensity of country $\mathcal{C}$, the emissions per unit of GDP. The downscaling is carried out individually for each gas $g$ (index omitted).

Figure 2 gives an overview of the steps of the downscaling process, which will be described in detail in the following sections. 


\section{Comparison of downscaling approaches}
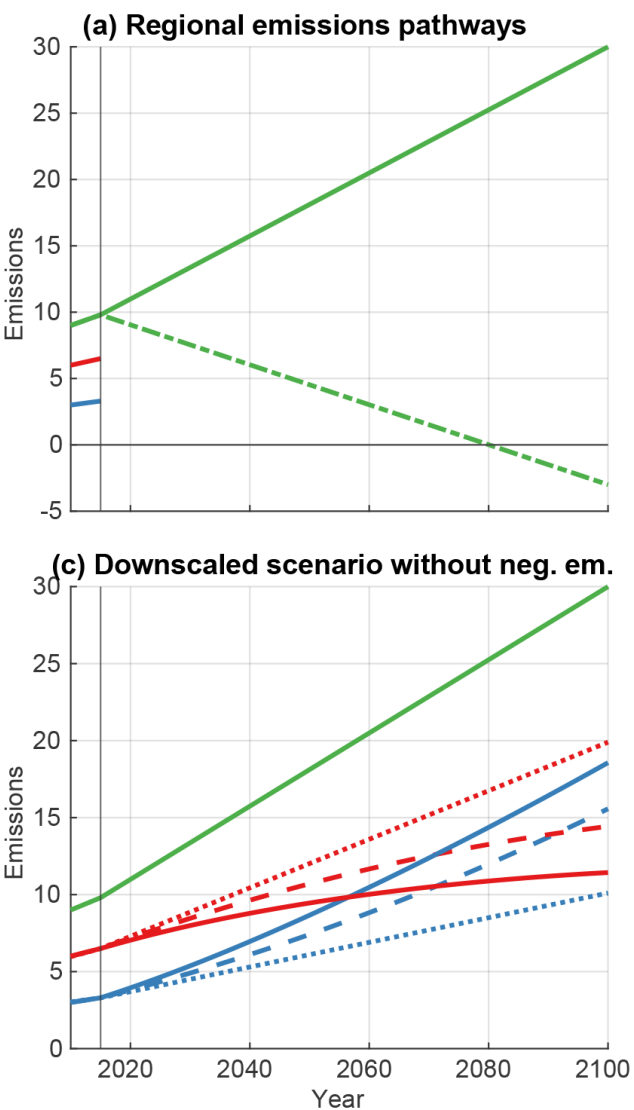

(b) GDP

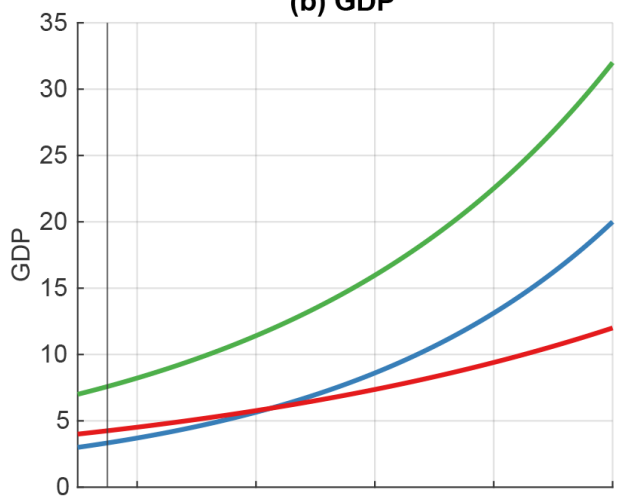

(d) Downscaled scenario with neg. em.

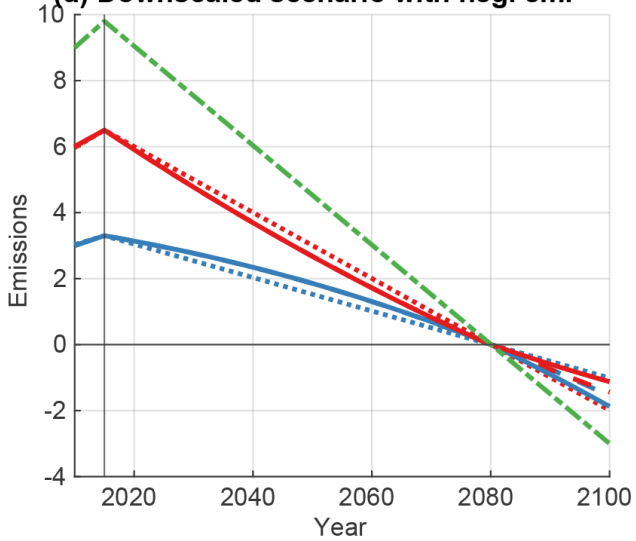

\begin{tabular}{|rll}
\hline Country 1 & $\ldots \ldots \ldots$ Constant shares & Region \\
Country 2 & $-m-m-$ Region neg. em. & --- Constant relative El
\end{tabular}

Figure 1. Example results for different downscaling approaches. For the sake of simplicity a two-country region is assumed. The constantrelative-emission-intensity downscaling is a variation of the external-input-based downscaling, where we use GDP as external input, and the assumption of constant relative emission intensities to create emission pathways based on the GDP data (b). Regional emission data are given for the whole time period, while for the countries only historical data are available (a). Panel (c) shows downscaling for increasing emissions. It is clearly visible that the constant-share downscaling does not account for the GDP development, while the convergence downscaling leads to the highest emissions of country 2 because it considers not only GDP growth but also converging emission intensities between the two countries. Panel (d) shows downscaling for a transition to negative emissions. For convergence downscaling the convergence is set to the year directly before the transition to negative emissions. The rapid reductions and early convergence lead to similar pathways for all methods before the transition to negative emissions. After the transition the effect of considering GDP is visible. The convergence year for convergence downscaling is 2150 in this example.

\subsubsection{Convergence and target emission intensity}

The year of convergence for the emission intensity within a region has to be chosen according to the SSP scenario storyline. We assign relatively early-convergence years (e.g., 2150) to scenarios with high economic integration, while scenarios with a regionalization storyline only justify partial convergence within the scenario timeframe. In the case that convergence is achieved during the scenario timeframe, all countries within a region converge to the regional emission intensity prescribed by the emission scenario. In the case of partial convergence we need to assume a regional emission intensity in a year after the end of the scenario. In van $\mathrm{Vu}$ uren et al. $(2006,2007)$ this was created using an exponential pathway with the average growth rate of the last years of the scenario. We judge exponential extrapolations to be very uncertain for long periods, especially when the variable to be extrapolated increases over time (as would be the case for, e.g., $\mathrm{CO}_{2}$ /GDP for, e.g., the RCP2.6 emission scenario with SSP4 basic elements GDP in the Asia region). We therefore use the emission intensity of the last scenario year as the target emission intensity if the convergence year is after the end of the scenario timeframe. For time series with a transition to negative emissions we have to adjust the convergence year 


\section{Convergence Downscaling Example}

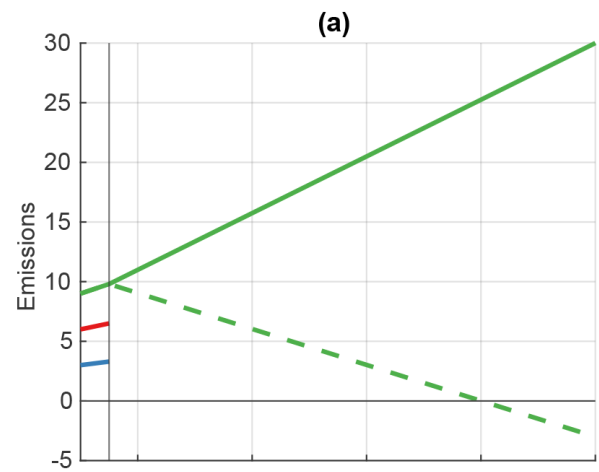

(c) Temporary Emissions Intensity

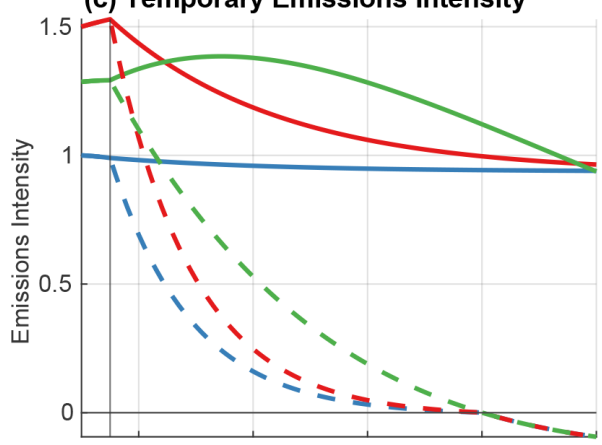

(e) Final Emissions

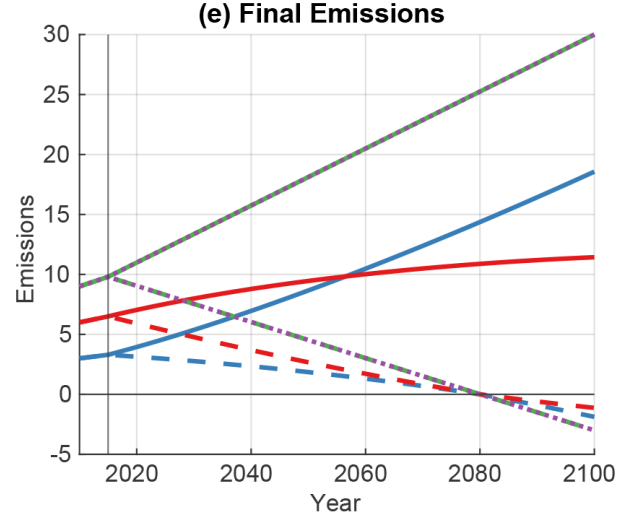

(b) GDP

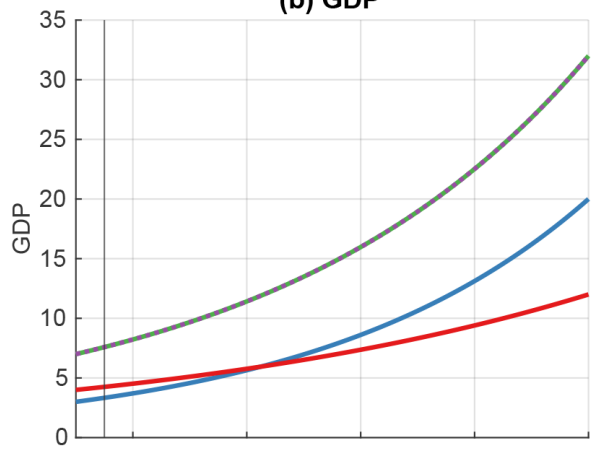

(d) Temporary Emissions

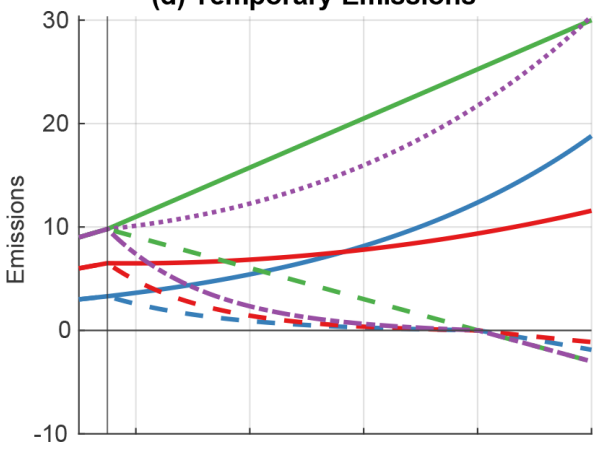

(f) Final Emissions Intensity

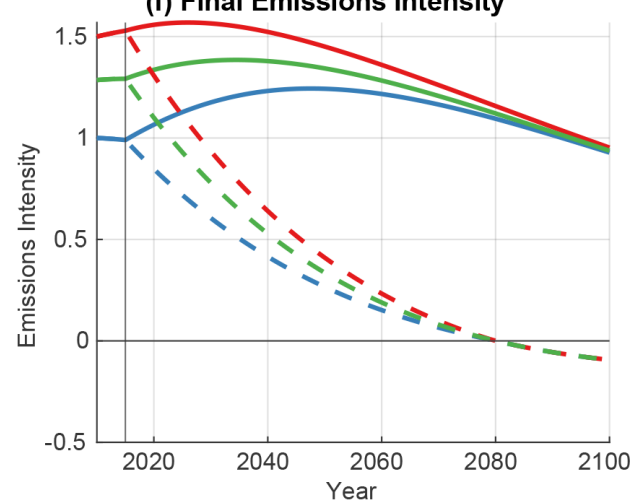

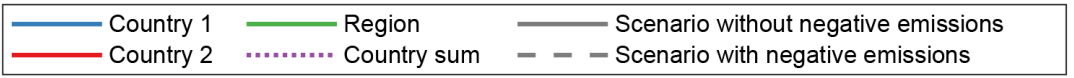

Figure 2. Steps of convergence downscaling of regional emission data using the IPAT equation and country GDP data for a two-country region for positive and negative regional emissions. Regional emission data are given for the whole time period, while for the countries only historical data are available (a). GDP data are given for both countries and the region for the whole time period (b). In the first step temporary emission intensity pathways for the countries are calculated using exponential convergence from historical values (2015). In the case of completely positive regional pathways, emission intensities converge to the regional value in a given convergence year (2150, c). In the case of negative emissions, convergence to the regional emission intensity is in the last year before the transition to negative emissions. After that year regional emission intensities are used. Multiplication with the given GDP time series creates temporary emission time series (d). These do not sum up to the regional values (see d) and have to be scaled to the regional value (results in e). This also changes the emission intensities (f). 
to avoid numerical instabilities and early (before regional total) transition to negative emissions for countries with emission intensities below the regional average. While this would make sense for countries which base their low emission intensity on a large share of renewable energy, it is not realistic for developing countries with very low emission intensities stemming from a low level of industrialization. We adjust the convergence year to be just before the regional transition to negative emissions.

\subsubsection{Construction of the temporary emission intensity pathways}

To generate the per country temporary emission intensity pathways, we need a method to interpolate between the initial emission intensity given by historical data and the target emission intensity in the convergence year given by the regional scenario. The methodology described in the following paragraphs is also presented graphically in Fig. 2.

Our method is based on the original approach by van Vuuren et al. (2007). The emission intensity pathway of a country is created using an exponential function that is defined by the initial emission intensity in the harmonization year and the regional emission intensity in the convergence year. The idea is that change in emission intensity is proportional to the difference of each country's emission intensity to the regional average.

The exponential convergence is modeled by the function

$\widehat{\mathrm{EI}}_{\mathcal{C}}(y)=a_{\mathcal{C}} e^{\gamma y}+b_{\mathcal{C}}, \quad$ for $\quad y_{\mathrm{h}}<y<y_{\mathrm{c}}$,

where $y_{\mathrm{h}}$ denotes the year of harmonization with historical data and $y_{\mathrm{c}}$ denotes the convergence year. The decay factor $\gamma$ is defined as

$\gamma=\frac{\ln (d)}{y_{\mathrm{c}}-y_{\mathrm{h}}}$

such that the exponential function reduces the difference between country and regional emission intensities from

$\operatorname{EI}_{\text {diff }}\left(y_{\mathrm{h}}\right)=\operatorname{EI}_{\mathcal{C}}\left(y_{\mathrm{h}}\right)-\operatorname{EI}_{\mathbb{R}}\left(y_{\mathrm{h}}\right)$

in the harmonization year $y_{\mathrm{h}}$ to $\operatorname{EI}_{\text {diff }}\left(y_{\mathrm{c}}\right)=d \mathrm{EI}_{\text {diff }}\left(y_{\mathrm{h}}\right)$ in the convergence year $y_{\mathrm{c}}$, where we chose $d=0.01$ to have almost complete convergence. Smaller values would lead to rapid partial convergence in the first years with only small changes in the later years. The country-specific constants $a_{\mathcal{C}}$ and $b_{\mathcal{C}}$ are defined via

$a_{\mathcal{C}}=\frac{\mathrm{EI}_{\mathbb{R}}\left(y_{\mathrm{c}}\right)-\mathrm{EI}_{\mathcal{C}}\left(y_{\mathrm{h}}\right)}{e^{\gamma y_{\mathrm{c}}}-e^{\gamma y_{\mathrm{h}}}}$

and

$b_{\mathcal{C}}=\frac{\mathrm{EI}_{\mathbb{R}}\left(y_{\mathrm{c}}\right)-d \mathrm{EI}_{\mathcal{C}}\left(y_{\mathrm{h}}\right)}{1-d}$.
In the case of convergence before the end of the scenario time span we continue all country time series with the regional emission intensity:

$\widehat{\mathrm{EI}}_{\mathcal{C}}(y)=\mathrm{EI}_{\mathbb{R}}(y)$, for $y \geq y_{\mathrm{c}}$.

For the part of the scenario also covered by historical data we use the historical emission intensity:

$\widehat{\mathrm{EI}}_{\mathcal{C}}(y)=E_{\mathcal{C}}(y) / \operatorname{GDP}_{\mathcal{C}}(y)$, for $y \leq y_{\mathrm{h}}$.

As an alternative to exponential convergence we also studied linear convergence of emission intensities. However we were not able to produce sensible results, as the scaling step (Sect. 2.3.3) exhibited numerical instabilities.

The result of this step is a set of temporary emission intensity pathways $\widehat{\mathrm{EI}}_{\mathcal{C}}$ for every country $\mathcal{C} \in \mathbb{R}$.

\subsubsection{Emission pathways and scaling}

Using the IPAT equation, we generate a preliminary emission pathway $\widehat{E}_{\mathcal{C}}$ for every country $\mathcal{C}$ :

$\widehat{E}_{\mathcal{C}}=\operatorname{GDP}_{\mathcal{C}} \widehat{\mathrm{EI}}_{\mathcal{C}}$

Those pathways are summed up to a preliminary pathway for the region $\mathbb{R}$ :

$\widehat{E}_{\mathbb{R}}=\sum_{\mathcal{C} \in \mathbb{R}} \widehat{E}_{\mathcal{C}}$

In general this pathway will differ from the regional pathway prescribed by the scenario. We create a scaling pathway

$S_{\mathbb{R}}=E_{\mathbb{R}} / \widehat{E}_{\mathbb{R}}$

The final country pathway is defined via

$E_{\mathcal{C}}=\widehat{E}_{\mathcal{C}} S_{\mathbb{R}}$

This method does not work in the case of negative emissions, which are common for $\mathrm{CO}_{2}$ pathways in low-emission scenarios like RCP2.6 or the new $1.9 \mathrm{~W} \mathrm{~m}^{-2}$ scenarios (Rogelj et al., 2018), where technologies like bio-energy with carbon capture and storage (BECCS) are assumed to remove large quantities of $\mathrm{CO}_{2}$ from the atmosphere. So the temporary $\mathrm{CO}_{2}$ emission pathways (see Eq. 10) of all countries in a region with negative emissions contain a transition to negative emissions and so does the regional-sum pathway (Eq. 11). Similarly, the regional pathway will be near zero for a few years before and after its transition to negative emissions. Therefore, the calculation of the scaling pathway (Eq. 12) is numerically unstable. As the country pathways are not necessarily near zero where their sum is zero, some adjusted country pathways will exhibit positive peaks in emissions, while others will contain negative-emission peaks, still summing to the correct regional value. These peaks are several years wide and can not be removed by interpolation without major changes to the country pathways. 
We have investigated several different options to circumvent this problem including dynamical downscaling algorithms, which downscale data year by year and can use alternate algorithms when regional emission intensity is near zero. However, fine tuning the parameters to deal with the transition to negative emissions for several scenarios proved to be very complicated, while the results were often very similar to the very simple solution of moving the convergence year to before the transition to negative emissions. After that year all countries follow the same emission intensity pathway. The steep reduction in emissions and emission intensity does not leave much freedom for the downscaling (see also Fig. 1). All countries have to rapidly reduce emissions to meet the prescribed regional pathway. Furthermore, as described in Sect. 2.3.1 there are conceptual problems with convergence years set to later than the transition to negative emissions. We therefore use the simple but transparent approach of early convergence. The calculation itself is not changed, but $y_{\mathrm{c}}$ is adjusted to be the last year before the transition to negative emissions. This is done on a per gas level. Only $\mathrm{CO}_{2}$ pathways have negative emissions; consequently only $y_{\mathrm{c}}$ of $\mathrm{CO}_{2}$ is adjusted. The downside of this approach is that it impacts the assumptions of convergence and eliminates the possibility to define different convergence speeds for different socio-economical storylines. Figure 2 gives an overview of the steps of the downscaling process.

\section{Input data and preprocessing}

This section provides an overview of the input data. It covers the RCP and SSP scenarios (Sect. 3.1) and their implementation including the choice of scenarios for international shipping and aviation (Sect. 3.1.3), the region definitions used in the models (Sect. 3.3), the countries covered by the datasets (Sect. 3.3), and the covered sectors and gases (Sect. 3.4). Furthermore, the historical data used to downscale the RCP and SSP scenarios are introduced in Sect. 3.2.

\subsection{Scenario description}

Two datasets are produced based on two sets of scenarios: RCPd, based on the RCP scenarios (van Vuuren et al., 2011a), which are downscaled using the SSP basic elements, and SSPv2d, based on the SSPv2 IAM implementations of the SSP scenarios, which come with consistent socioeconomic data that are used for downscaling (Riahi et al., 2017; Rogelj et al., 2018).

Not all combinations of RCP GHG forcing scenarios and SSP storylines are meaningful, as some SSP storylines imply, e.g., emissions that lead to forcing levels below RCP8.5, while other SSPs imply high unmitigated emissions, for which it is unrealistic to be mitigated to the lowest RCP forcing levels without substantially changing the socio-economic storyline. For the SSPv2 scenarios the possible combinations were determined by the IAMs: the SSP-specific baseline sce- narios define the maximal forcing level for each SSP, while the minimal level was found implicitly because the forcing level of low RCPs could not be attained for all SSPs.

\subsubsection{SSPv2 IAM runs (SSPv2d)}

During the integrated assessment model (IAM) implementations of RCP-SSP combinations (SSPv2) it was found that some combinations can not be implemented. Figure 8 in Riahi et al. (2017) illustrates the carbon prices needed to reach a certain mitigation level under a given SSP. The figure also shows that the RCP8.5 forcing is only reached for SSP5. All other SSPs have baseline emissions leading to a lower climate forcing. For SSP1, RCP6 is the baseline; for SSP24, the baseline forcings are between RCP6 and RCP8.5. Under SSP3, the low-emission scenario of RCP2.6 can not be attained, and under SSP5 one model was unable to attain sufficiently low emissions. The IAM implementations of SSP scenarios use an additional intermediate forcing level of $3.4 \mathrm{~W} \mathrm{~m}^{-2}$ (Riahi et al., 2017), which can be reached under all SSP storylines. Additionally, SSPv2 contains a new strong mitigation pathway reaching a forcing level of only $1.9 \mathrm{~W} \mathrm{~m}^{-2}$ (Rogelj et al., 2018). This forcing level is attained for SSP1, 2, and 5. Only a single model could attain a forcing of $1.9 \mathrm{~W} \mathrm{~m}^{-2}$ under SSP4, and no model could under SSP3 (see Rogelj et al., 2018, Fig. 5).

We downscale all SSPv2 runs, both marker and other. An overview is shown in Table 1 . However, not all scenarios have been implemented by all modeling groups (see Appendix B1). For each SSP a different IAM provided the respective illustrative marker scenario. Namely those were for SSP1: IMAGE (Integrated Model to Assess the Global Environment; van Vuuren et al., 2017), SSP2: MESSAGE (Model for Energy Supply Strategy Alternatives and their General Environmental Impact; Fricko et al., 2017), SSP3: AIM/CGE (Asia-Pacific Integrated Model/Computable General Equilibrium; Fujimori et al., 2017), SSP4: GCAM4 (Global Change Analysis Model; Calvin et al., 2017), and SSP5: REMIND-MAgPIE (Regional Model of Investment and Development; Model of Agricultural Production and its Impacts on the Environment; Kriegler et al., 2017).

\subsubsection{RCP and SSP basic elements (RCPd)}

To select sensible combinations of RCP scenarios and SSPbasic-elements scenarios we use the SSPv2 IAM runs as a basis. The combination of RCP8.5 with SSP1 is excluded because no model reached emissions significantly above RCP6 levels, and the SSP1 storyline of a rapid sustainable development is not compatible with RCP8.5 emission levels. The baseline forcings of SSP2-4 do not reach $8.5 \mathrm{~W} \mathrm{~m}^{-2}$; however, forcings are significantly above $6 \mathrm{~W} \mathrm{~m}^{-2}$ for SSP2 $\left(6.5-7.3 \mathrm{~W} \mathrm{~m}^{-2}\right)$ and SSP3 $\left(6.7-8.0 \mathrm{~W} \mathrm{~m}^{-2}\right)$ (Riahi et al., 2017). Thus we include the combination of RCP8.5 with SSP2 and 3. SSP4 models a very unequal socio-economic de- 
Table 1. Forcing levels attained by SSPv2 studies. See Riahi et al. (2017), Calvin et al. (2017), and Rogelj et al. (2018). For SSP1, RCP6 is the baseline forcing for all models except WITCH (World Induced Technical Change Hybrid), which has a slightly higher baseline (BL) such that RCP6 is a mitigation scenario. "x" means that the forcing level could be attained by all models that implemented it, and " $(\mathrm{x})$ " means that it could be attained by at least one model but not in the marker implementation. All forcings in $\mathrm{W} \mathrm{m}^{-2}$.

\begin{tabular}{lccccc}
\hline & SSP1 & SSP2 & SSP3 & SSP4 & SSP5 \\
\hline Baseline & 5.8 & $6.5-7.3$ & $6.7-8.0$ & 6.4 & 8.5 \\
RCP8.5 & & & & & $\mathrm{x}=\mathrm{BL}$ \\
RCP6 & $(\mathrm{x})=\mathrm{BL}$ & $\mathrm{x}$ & $\mathrm{x}$ & $\mathrm{x}$ & $\mathrm{x}$ \\
RCP4.5 & $\mathrm{x}$ & $\mathrm{x}$ & $\mathrm{x}$ & $\mathrm{x}$ & $\mathrm{x}$ \\
$3.4 \mathrm{~W} \mathrm{~m}^{-2}$ & $\mathrm{x}$ & $\mathrm{x}$ & $\mathrm{x}$ & $\mathrm{x}$ & $\mathrm{x}$ \\
RCP2.6 $^{-2}$ & $\mathrm{x}$ & $\mathrm{x}$ & & $\mathrm{x}$ & $(\mathrm{x})$ \\
$1.9 \mathrm{~W} \mathrm{~m}^{-2}$ & $\mathrm{x}$ & $\mathrm{x}$ & & $(\mathrm{x})$ & $\mathrm{x}$ \\
Marker & IMAGE & MESSAGE & AIM/CGE & GCAM4 & REMIND \\
\hline
\end{tabular}

Table 2. Combination of RCP scenarios with SSP-basic-elements country results considered in this study.

\begin{tabular}{lccccc}
\hline & SSP1 & SSP2 & SSP3 & SSP4 & SSP5 \\
\hline RCP8.5 & & $\mathrm{x}$ & $\mathrm{x}$ & & $\mathrm{x}$ \\
RCP6 & $\mathrm{x}$ & $\mathrm{x}$ & $\mathrm{x}$ & $\mathrm{x}$ & $\mathrm{x}$ \\
RCP4.5 & $\mathrm{x}$ & $\mathrm{x}$ & $\mathrm{x}$ & $\mathrm{x}$ & $\mathrm{x}$ \\
RCP2.6 & $\mathrm{x}$ & $\mathrm{x}$ & & $\mathrm{x}$ & $\mathrm{x}$ \\
\hline
\end{tabular}

velopment with low reference emissions, as only a small part of the world has high consumption levels, and cheap mitigation options, as investment in new technologies is high. The baseline forcing of $6.4 \mathrm{~W} \mathrm{~m}^{-2}$ (Calvin et al., 2017) is above RCP6 but significantly below RCP8.5. We thus exclude the combination of SSP4 with RCP8.5.

In the IAM studies it was also found that the SSP3 storyline does not allow for sufficient mitigation to reach RCP2.6 forcing levels (Riahi et al., 2017). Consequently, we exclude this combination. The combination of SSP5 with RCP2.6 is included, as most models used for SSPv2 can attain the necessary forcing levels. All combinations considered are shown in Table 2.

Figure 3 gives an overview of the RCP and SSPv2 scenarios. Figures for individual gases are available in Sect. S2.1 in the Supplement.

\subsubsection{Emissions from international shipping and aviation}

Emissions from international shipping and aviation (bunker fuels) are not attributed to individual countries under the UNFCCC. Therefore they need special consideration in the downscaling process.

- RCPd. Emissions from international shipping and aviation are included in the RCP scenario emissions. For $\mathrm{CO}_{2}$ and $\mathrm{N}_{2} \mathrm{O}$ (marine only) however, they are not provided as individual emission time series but included in the regional emissions. As growth rates of emissions from aviation and shipping likely differ from growth rates of general fossil $\mathrm{CO}_{2}$ emissions, the inclusion changes the growth rates of the regional emission pathways. As there are no readily available consistent $\mathrm{CO}_{2}$ pathways for international shipping and aviation for the original RCP scenarios, they have to be either generated or taken from other scenarios. The RCPs provide data for several gases and pollutants for aviation and shipping. One approach is to try to calculate $\mathrm{CO}_{2}$ emissions consistent with the RCP emissions from other gases using correlations between $\mathrm{CO}_{2}$ and the other gases obtained from scenarios which cover all gases. However, using the shipping and aviation time series from Owen et al. (2010) and QUANTIFY (2010) to compute the correlations, no consistent $\mathrm{CO}_{2}$ pathways could be generated, as results based on different gases were not consistent. We therefore have to use external scenarios. We use the CMIP6 emission scenarios from Gidden et al (2019), which are based on the RCP forcing and SSP storylines and are consistent with the RCPs on the basis of RCP forcing targets but not the pathways to reach these targets. See Table 3 for our choice of CMIP6 bunker scenarios for the RCPs.

The CMIP6 scenarios contain emissions for international shipping for $\mathrm{CO}_{2}$ and $\mathrm{CH}_{4}$ as well as aviation emissions for $\mathrm{CO}_{2}$. Unfortunately $\mathrm{N}_{2} \mathrm{O}$ emissions are only given as a national total. We thus compute a factor of $\mathrm{N}_{2} \mathrm{O}$ over $\mathrm{CO}_{2}$ from historical data (2007-2012 average from Smith et al., 2014) and construct scenarios from the $\mathrm{CO}_{2}$ scenarios, assuming this factor is constant over time. As $\mathrm{N}_{2} \mathrm{O}$ emissions only contribute roughly $1 \%$ of total bunker emissions this simplification has very limited impact. To downscale total aviation emissions to domestic and international aviation, we use the shares from the historical CMIP6 emission data (Hoesly et al., 2018).

- SSPv2d. The SSPv2 scenarios as presented in the SSPDB (International Institute for Applied Systems 

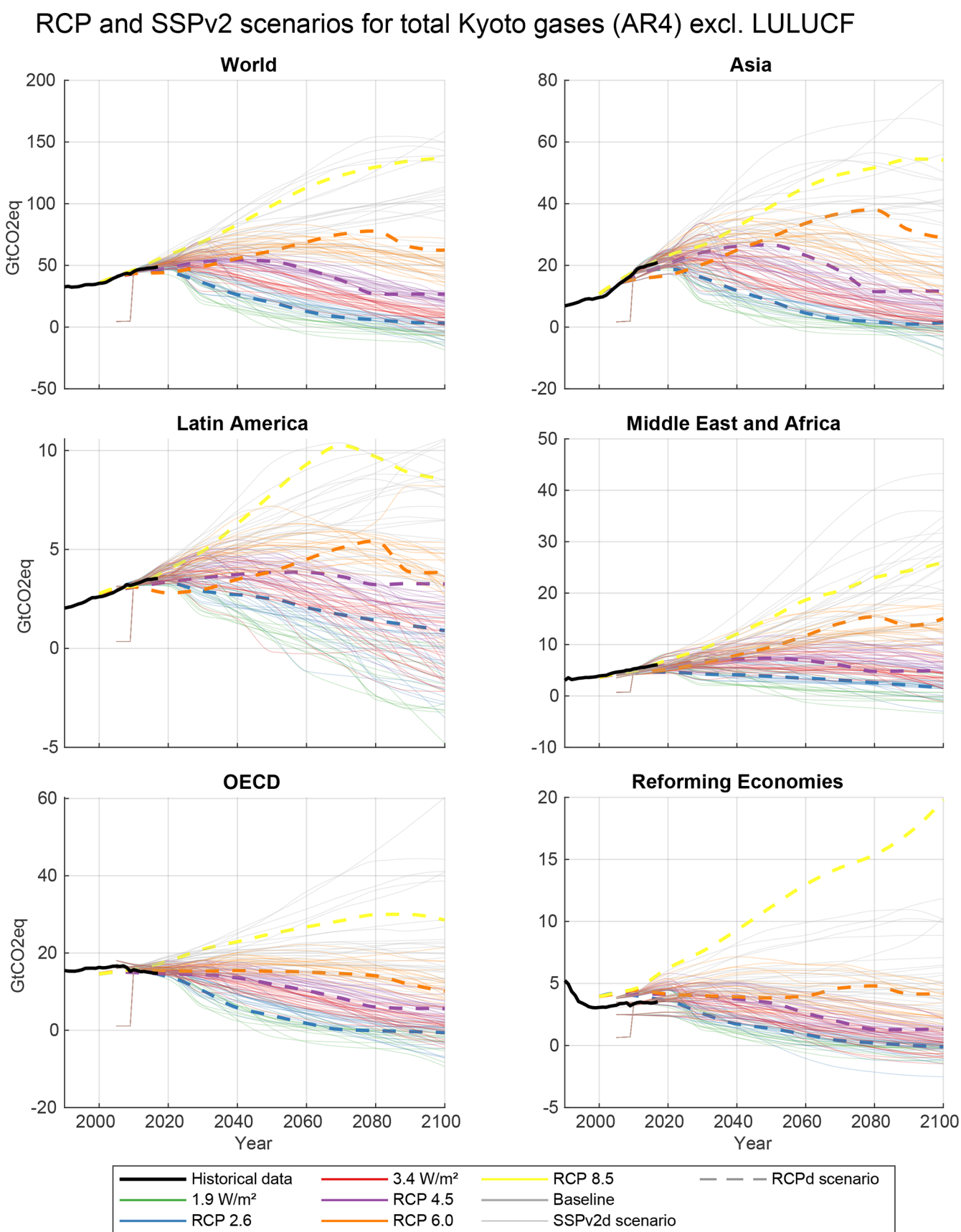

$$
\begin{aligned}
& \text { RCP } 8.5 \\
& \text { Baseline } \\
& \text { SSPv2d scenario }
\end{aligned}
$$

Figure 3. RCP and SSPv2 scenarios for total Kyoto GHG emissions (AR4 GWPs; global warming potentials) excluding LULUCF (land use, land use change, and forestry). Scenarios are not harmonized to historical data. Historical data shown are from PRIMAP-hist with bunker fuel $\mathrm{CO}_{2}$ emissions added from CDIAC (Carbon Dioxide Information Analysis Center) data (Boden et al., 2017; Andres et al., 1999; Marland and Rotty, 1984).

Analysis SSP scenario database; IIASA, 2018; Riahi et al., 2017) do not include explicit bunker emissions. As for the RCPs we use the CMIP6 scenarios, which also offer implementations of the new 1.9 and $3.4 \mathrm{~W} \mathrm{~m}^{-2}$ forcing targets. We base the bunker emissions on the forcing targets only and use the same emission time series for all SSPs. The methods are generally the same as for the RCP scenarios with a few small adjustments. External scenarios are needed for all gases including $\mathrm{CH}_{4}$, which has explicit data in the RCP scenarios but not in SSPv2. For the SSP baseline scenarios we use the SSP3 baseline implementation reaching $7.0 \mathrm{~W} \mathrm{~m}^{-2}$ for all SSPs. The choice of scenarios is shown in Table 3. 
Table 3. Choice of SSP-CMIP6 bunker pathways to complement the RCPs and SSPv2 scenarios with $\mathrm{CO}_{2}, \mathrm{~N}_{2} \mathrm{O}$, and $\mathrm{CH}_{4}$ emissions. $\mathrm{CH}_{4}$ is only needed for the SSPv2 scenarios, as data are available for the RCPs. Baseline emissions are between RCP6 and RCP8.5 for most SSPs. GLOBIOM: GLObal BIOsphere Model.

\begin{tabular}{ll}
\hline RCP & Aviation and shipping scenario \\
\hline Baseline & SSP3 7.0 BL AIM/CGE \\
RCP8.5 & SSP5 8.5 BL REMIND-MAgPIE \\
RCP6 & SSP4 6.0 GCAM4 \\
RCP4.5 & SSP2 4.5 MESSAGE-GLOBIOM \\
$3.4 \mathrm{~W} \mathrm{~m}^{-2}$ & SSP4 3.4 GCAM4 \\
RCP2.6 & SSP1 2.6 IMAGE \\
$1.9 \mathrm{~W} \mathrm{~m}^{-2}$ & SSP1 1.9 IMAGE \\
\hline
\end{tabular}

In the scenarios from two of the models (IMAGE and AIM/CGE) there is a slight ( $<1 \mathrm{GtCO}_{2}$ eq.) discrepancy between global emissions and the sum of the regional emissions. The discrepancy is decreasing in time towards 2100 . International bunkers are a good explanation for additional global emissions. However, the discrepancies are much smaller than any bunker estimate, especially in the future. We thus discard the global data and work with the regional data as for all other scenarios.

The bunker scenarios are shown in Fig. 4.

To create scenarios excluding bunker emissions, we subtract the bunker emissions from the regional pathways using the historical $\mathrm{CO}_{2}$ bunker emissions from CDIAC (Boden et al., 2017; Andres et al., 1999; Marland and Rotty, 1984) (2004-2014 average) to downscale the global aviation and shipping pathway to the region level. This does not take into account the development of regional emissions and regional economies, but as it is unclear how the international bunker emissions were calculated and assigned to regions when creating the RCP data, a more sophisticated method would not necessarily lead to better results.

Bunker emissions also depend on the socio-economic storyline, not only the emission scenario, so selecting the bunker pathways solely based on the RCP forcing levels and not based on the SSP storylines, which govern, e.g., trade patterns, is a simplification. There are two reasons for this: firstly, for gases that are not well mixing (i.e., all except $\mathrm{CO}_{2}$ and $\mathrm{N}_{2} \mathrm{O}$, but of these we only use $\mathrm{CH}_{4}$ here) bunker data are already given for the RCPs, and, secondly, there are no bunker scenarios available for all different RCP-SSP combinations, so basing the selection of bunker scenarios on both RCP and SSP would require several assumptions.

\subsection{Historical data}

Our aim is to create a set of scenarios that is directly usable for climate policy research and analysis. It is important that the country-specific pathways are in line with historical data for both emissions and socio-economic variables. We do not use the historical data provided with the RCP and SSP scenarios, as we want to use latest historical compilation datasets (Gütschow et al., 2019, 2016).

\subsubsection{Historical emission data}

We use the PRIMAP-hist (v2.1) historical emission time series (Gütschow et al., 2016, 2019). It combines multiple data sources into one comprehensive dataset covering all Kyoto GHGs, all sectors, all countries, and all years from 1850 to 2017. Emission data for some gases and sectors are interpolated for the last years. The highest priority during the combination of time series from different sources is given to data which have been reported to the UNFCCC by countries. The dataset can be viewed on Paris Reality Check (PRIMAP, 2020) and is openly accessible (Gütschow et al., 2019).

\subsubsection{Historical socio-economic data}

We use the PRIMAP-hist historical socio-economic time series (Gütschow, 2019). It is constructed using the same methods as the PRIMAP-hist emission time series.

For population data we use the UN population prospects (UN DESA/Population Division, 2019) and fill gaps and missing countries from the database of the World Bank's World Development Indicators (WDIs) (The World Bank, 2019b, a). HYDE 3.2 (History Database of the Global Environment) data are used for extrapolation into the past until 1850 (Klein Goldewijk et al., 2017; Klein Goldewijk, 2017).

GDP data are based on purchasing-power-parity-adjusted (PPP-adjusted) data from the Penn World Table (Feenstra et al., 2015, 2019). Missing data are filled using the 2018 Maddison Project database (Bolt et al., 2018b, a) and WDIs. Finally we fill missing historical data from a processed version of the older Maddison Project data (Geiger, 2018; Geiger and Frieler, 2017; Bolt and van Zanden, 2014; Maddison Project, 2013; see also Gütschow, 2019). The choice of PPP-adjusted GDP has two reasons: firstly, for compatibility reasons, as the SSP data are given in PPP-corrected form, and, secondly, PPP-adjusted GDP is more comparable between countries than market-exchange-rate-based (MERbased) GDP, which is important for the downscaling process as the process assumes convergence of emission intensities.

\subsection{Regions and country coverage}

Here, we provide information on the regions used for the input data and the conditions under which countries are included in the input data and the final dataset. For a country to be available in the final time series it needs to be included in the SSP-basic-elements GDP time series and the historical data for both emissions and GDP, and for the SSPv2 scenarios it further needs to be included in the region definitions of the IAMs. Table S2 of the Supplement gives an overview of 


\section{Bunker fuel emissions scenarios}
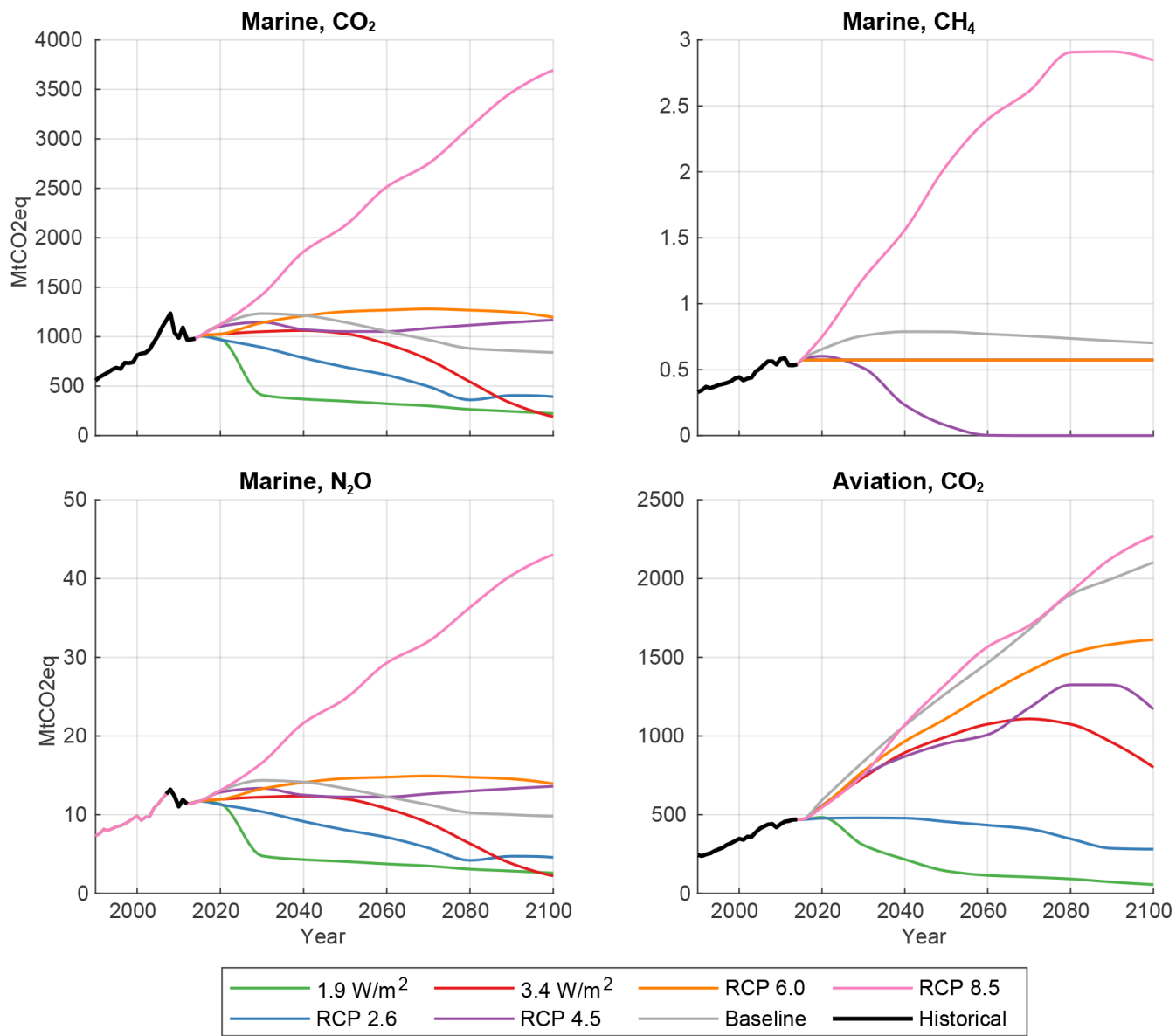

Figure 4. Scenarios for bunker fuels used to remove bunker emissions from the RCP and SSPv2 emission scenarios. Aviation emissions are only available for $\mathrm{CO}_{2}$. Historical data are from CMIP6 (Hoesly et al., 2018) for $\mathrm{CO}_{2}$ and $\mathrm{CH}_{4}$. For $\mathrm{N}_{2} \mathrm{O}$ we use data from the International Maritime Organization (IMO) and EDGAR v4.3.2 data (Emissions Database for Global Atmospheric Research; JRC and PBL, 2017; Janssens-Maenhout et al., 2019) for the time not covered by the IMO data.

available countries in each scenario, the input data, and the final dataset.

\subsubsection{RCPd}

The emission pathways provided with the RCP scenarios divide the world into five regions (IIASA, 2009):

- ASIA: Asian countries

- LAM: Latin America

- MAF: Middle East and Africa

- OECD90: OECD (Organisation for Economic Cooperation and Development) countries as of 1990 and some Pacific island states

- REF: reforming economies (former Soviet Union).
Each of these regions is downscaled individually and not influenced by values from other regions. Where countries are missing in the socio-economic pathways or the historical emission data, they are ignored, and the regional emissions are split among the available countries. The SSP basic elements do not cover all countries but, depending on the modeling group, leave out some smaller countries. This excludes several small states such as most of the small island states. Those states are therefore excluded from the downscaled dataset. A list of those countries can be found in Sect. S1.3.7 in the Supplement. Some countries do not have data for all variables and are included in the final datasets with the available variables.

The socio-economic scenarios provided by the SSPbe modeling groups contain population (KC and Lutz, 2017) and GDP (Dellink et al., 2017; Leimbach et al., 2017; Crespo Cuaresma, 2017) projections on a per country or detailed per region level. Population data are only provided 
by the IIASA (International Institute for Applied Systems Analysis) group; the other groups (OECD and PIK) use the IIASA population projections to build their GDP projections. GDP data are provided in purchasing-power-parity-corrected (PPP-corrected) form in 2005 international dollars (GearyKhamis dollar; GKD) ${ }^{1}$. The PIK data are provided on a level of 32 world regions. We downscale it to the individualcountry level using the underlying IIASA population data and the method introduced in Sect. 4.2. In Sect. S1.2 in the Supplement we present the exact region definitions and list of missing countries for each modeling group.

\subsubsection{SSPv2d}

The SSPv2 IAM implementations provide both emission and socio-economic data on the level of five world regions similar to the regions used in the RCPs. However, the exact region definitions in terms of included countries differ from model to model. A detailed list with region definitions is available from the SSP database (IIASA, 2016). We use the model-dependent region definitions to downscale both socioeconomic and emission data. GDP data are provided in PPPcorrected form in 2005 dollars (GKD and USD). The socioeconomic data of the SSPv2 runs is based on the IIASA country population data (KC and Lutz, 2017) and the OECD GDP data (Dellink et al., 2017). Consequently, we use these datasets to downscale the IAM data to the country level using an external-input-based downscaling method (see Sect. 4.3). In Sect. S1.3 in the Supplement we present a list of missing countries for each model.

\subsection{Sectors and gases}

The sector and gas resolution of the historical time series is finer than the resolution of the scenarios for all sectors, gases, and countries. Thus, the resolution of the final dataset is determined by the resolution of the scenario data. In this section we are only considering emission time series, as population and GDP are given as national totals.

LULUCF emissions are subject to high annual fluctuations, and their development very much depends on individual countries' policies. Furthermore, the scenario data often have positive emissions for regions for which historical data show negative emissions in the past years. In this case the past (negative) emission shares and emission intensity are no indicator for projected (positive) emissions. LULUCF downscaling thus needs several strong assumptions which we think users of the data should make knowingly instead of unknowingly using our assumptions. In conclusion we exclude LULUCF data from the downscaling as done in van Vuuren et al. $(2006,2007)$.

\footnotetext{
${ }^{1}$ Actually, data are provided in 2005 US dollars (USD), but for a PPP-corrected GDP this equals 2005 international dollars (GKD).
}

\subsubsection{RCPd}

The RCPs include information for the Kyoto GHGs $\left(\mathrm{CO}_{2}\right.$, $\mathrm{CH}_{4}, \mathrm{~N}_{2} \mathrm{O}$, and the fluorinated gases (F-gases)) as well as several other substances $\left(\mathrm{CO}, \mathrm{SO}_{2}, \mathrm{NH}_{3}, \mathrm{NO}_{x}\right.$, black carbon (BC), organic carbon (OC), volatile organic compounds (VOCs), and ozone-depleting substances (ODSs)). Here we focus on the Kyoto GHGs because of their special relevance to the UNFCCC negotiations and availability of historical data. Additional substances can be added if there is demand from the scientific community and where historical data are available (for historical data see Hoesly et al., 2018; Meinshausen et al., 2017). Fluorinated gases are treated as one gas at the moment. Historical data for fluorinated gases are available at a level of aggregate HFCs (hydrofluorocarbons), aggregate $\mathrm{PFCs}$ ((per-)fluorocarbons), and $\mathrm{SF}_{6}$ for all countries, but to be consistent with the SSPv2 scenarios which only provide aggregate data for fluorinated gases, we do not use this more detailed data in the downscaling process. Some substances such as black carbon need other downscaling methods, as they are often co-emitted with gases like $\mathrm{CO}_{2}$. This correlation of emissions has to be taken into account in the downscaling.

The sectoral detail of the emission data provided with the RCPs differs between the greenhouse gases. The data for the most important gas, $\mathrm{CO}_{2}$, are only resolved into emissions from land use, land use change, and forestry (LULUCF) and emissions from fossil fuels and industry. We employ the same sectoral resolution for the other Kyoto GHGs. $\mathrm{N}_{2} \mathrm{O}$ data are only available as a national total. As LULUCF emissions only constitute a fraction of roughly $3 \%$ of global $\mathrm{N}_{2} \mathrm{O}$ emissions (in 2015, see Gütschow et al., 2018), we use the total emissions as a proxy for fossil fuel and industrial emissions.

\subsubsection{SSPv2d}

In principle the SSPv2 scenarios cover the same substances as the RCP scenarios. However, fluorinated gases are only available as a global-warming-potential-weighted aggregate time series. Therefore, fluorinated gases (F-gases) are treated as one substance. While the global warming potential (GWP) used for the F-gas basket is not explicitly given, the data are consistent with a Kyoto GHG basket ${ }^{2}$ created using GWPs from the IPCC's "Fourth Assessment Report" (AR4). Therefore, we assume that the F-gas basket has been calculated based on AR4 GWPs.

In terms of sectors the SSPv2 scenarios offer less detail than the RCPs: $\mathrm{CO}_{2}, \mathrm{CH}_{4}$, and $\mathrm{N}_{2} \mathrm{O}$ emissions are available for the national total and a sector called "land use" independently. For $\mathrm{CO}_{2}$ and for some scenarios also for $\mathrm{CH}_{4}$, additional time series for emissions from fossil fuels and industry are provided. However, the employed definition of the land use sector differs from the definition in the IPCC categoriza-

\footnotetext{
${ }^{2}$ The Kyoto GHG basket is the GWP-weighted sum of $\mathrm{CO}_{2}$, $\mathrm{CH}_{4}, \mathrm{~N}_{2} \mathrm{O}$, and the fluorinated gases (HFCs, PFCs, and $\mathrm{SF}_{6}$ ).
} 
tions. The high emission levels for $\mathrm{CH}_{4}$ and $\mathrm{N}_{2} \mathrm{O}$ suggest that, rather than for land use only, the time series cover emissions from the agriculture, forestry, and land use (AFOLU) sector. For $\mathrm{CO}_{2}$ this is not a practical problem, as agricultural $\mathrm{CO}_{2}$ emissions contribute less than $0.1 \%$ to total $\mathrm{CO}_{2}$ emissions (Gütschow et al., 2019), and we use the land use sector as a proxy for LULUCF. However, for $\mathrm{N}_{2} \mathrm{O}$ and $\mathrm{CH}_{4}$ this is not possible, as agricultural contributions are substantial. We thus use national total emissions as a proxy for fossil fuel and industrial emissions, as LULUCF emissions for these gases account for only $3 \%\left(\mathrm{~N}_{2} \mathrm{O}\right)$ and $4 \%\left(\mathrm{CH}_{4}\right)$ of national total emissions (Gütschow et al., 2018). Emissions of fluorinated gases are available as a national total only, which suffices, as they originate from industrial sources only.

\section{Downscaling of RCP and SSPv2 scenarios}

The following describes the generation of the downscaled RCP and downscaled SSPv2 scenarios step by step from the preparation of input data to the combination of historical and scenario data for the final time series.

- Data preparation. The RCP and SSP data are processed as described in Sect. 4.1. Historical data do not need preprocessing at this step.

- Downscaling of socio-economic data. Not all socioeconomic data have country resolution. The PIK GDP data need downscaling to the country level (Sect. 4.2), and the SSPv2 socio-economic data need it as well (Sect. 4.3). After the downscaling, all socio-economic data are processed to match the country definitions of the historical emission data.

- Generation of socio-economic scenarios. In this step GDP and population time series from all SSP scenarios are combined with historical data (Sect. 4.4). The socio-economic part of the dataset is finalized with this step and is used as input for the emission downscaling.

- Downscaling of RCP and SSPv2 emission data. RCP data are downscaled using the SSP-basic-elements country data (Sect. 4.5), while SSPv2 data are downscaled using the downscaled SSPv2 socio-economic data (Sect. 4.3). During the process the downscaling key is harmonized to historical data (Sect. 4.4).

- Generation of emission scenarios. In the final step the downscaled RCP and downscaled SSPv2 emission scenarios are combined with and harmonized to historical emission data (Sect. 4.6).

All operations are carried out independently per scenario, region and gas. The combination of historical and scenario data is carried out independently per scenario, country, and gas.

\subsection{Preparation of RCP and SSP data}

RCP and SSP data have to be preprocessed such that data are available for all sectors, gases, and years needed for the downscaling.

\subsubsection{RCP data}

The RCP data only offer values every 10 years. It is interpolated using MATLAB's "pchip" function to obtain yearly values needed for harmonization. The data do not resolve any categories for $\mathrm{N}_{2} \mathrm{O}$ and fluorinated gases. National total values are copied to obtain values for emissions excluding land use for fluorinated gases and $\mathrm{N}_{2} \mathrm{O}$. For methane higher-level categories are aggregated from the lower-level categories available in the RCP data. We build the HFC, PFC, aggregate F-gas, and Kyoto GHG baskets for GWPs from the IPCC's "Second Assessment Report" (SAR) and "Fourth Assessment Report" (AR4)

Time series excluding bunker emissions are created in accordance with Sect. 3.1.3.

\subsubsection{SSP basic elements}

The SSP-basic-elements country-level data are first summed to the country definitions used for the historical GDP and population data. GDP data are given in PPP-corrected 2005 US dollars (USD) and have to be converted to 2011 international dollars (GKD) (see Appendix C1 for details). As IIASA and OECD data cover a slightly different set of countries, we create a composite GDP source which uses the OECD GDP data as the basis and fills missing countries from the IIASA data. See Table 2 of the Supplement for details.

\subsubsection{SSPv2 socio-economic data}

The SSPv2 socio-economic scenarios are interpolated to obtain yearly values from time series with a temporal resolution of 10 years. No further processing is done at this point.

\subsubsection{SSPv2 emission data}

The SSPv2 emission data are interpolated to obtain yearly values. $\mathrm{N}_{2} \mathrm{O}$ and $\mathrm{CH}_{4}$ emissions excluding LULUCF are obtained from national total emissions. Existing time series are discarded because they do not include agricultural emissions. Fluorinated gases are only available as a AR4 GWPweighted sum. To create a time series for SAR GWPs, regional conversion factors from AR4 to SAR are calculated from EDGAR v4.2 data for individual gases using the years 2000 to 2012. As for $\mathrm{CH}_{4}$ and $\mathrm{N}_{2} \mathrm{O}$, a copy of national total F-gas emissions is used for the national total excluding LULUCF. We build Kyoto GHG baskets for SAR and AR4 GWPs.

Time series excluding bunker emissions are created in accordance with Sect. 3.1.3. 


\subsection{Downscaling of PIK GDP data}

The PIK GDP data are not available on a per country level but only for 32 regions. These regions are downscaled to the country level using external-input downscaling (see Sect. 2.2) with country shares from the OECD GDP data (complemented by IIASA data for missing countries).

The results of the GDP downscaling are in line with the GDP projections of the two other modeling groups. The pathways show similar developments, and the spread between different scenarios is similar to the other modeling groups. This is to be expected, as we use the country data from OECD and IIASA as external input to the downscaling. For results see Figs. 6 and 7.

\subsection{Downscaling of SSPv2 GDP and population data}

The population and GDP data used as input to the SSPv2 IAM runs are based on the SSP-basic-elements results. IIASA population data (KC and Lutz, 2017) and OECD GDP data (Dellink et al., 2017) are used. In theory the data used by the IAMs should be identical to the country model data; however, different region specifications can introduce small changes in the data. We thus do not take the country data directly but use it as the key in an external-input-based downscaling of the IAM data: the regional GDP and population time series from the IAM scenarios are downscaled to the country level using shares from the country model results. We use model-specific region definitions for the downscaling (see Sect. 3.3.2 and the Supplement).

\subsection{Harmonization}

Harmonization of scenario data to historical data is used in several places throughout this study. Whenever IPAT-based downscaling is used, the downscaling key is harmonized to historical data. This is necessary to ensure that the concept of converging emission intensities holds for the final scenarios, in which both socio-economic and emission data are harmonized to and combined with historical data. Downscaling with external or constant shares does not need this harmonization step, as both methods do not use socio-economic data. For the RCP and SSPv2 emission downscaling this means that the resulting downscaled data are consistent with the harmonized GDP data, not with the raw SSPv2 GDP data. The effect of GDP harmonization is shown in Sect. S2.3 in the Supplement.

We also create time series where scenario data are harmonized to historical data for socio-economic and emission data. The harmonization techniques and parameters are similar for socio-economic and emission data. The harmonization year is always 2017. For the historical value we do not directly use the 2017 data but calculate a value using a 13-year linear trend (2005-2017) to weaken the influence of shortterm fluctuations in data. From this value $\left(E_{\mathrm{h}, \text { hist }}\right)$ and the 2017 scenario value $E_{\mathrm{h} \text {,scen }}=E_{\text {scen }}(2017)$ a harmonization
Table 4. Convergence years for IPAT-based convergence downscaling for the different SSPs.

\begin{tabular}{lrrrrr}
\hline Scenario & SSP1 & SSP2 & SSP3 & SSP4 & SSP5 \\
\hline Year & 2150 & 2200 & 2300 & 2300 & 2150 \\
\hline
\end{tabular}

factor is calculated: $f_{\mathrm{h}}=E_{\mathrm{h} \text {,hist }} / E_{\mathrm{h} \text {,scen }}$. For socio-economic data we use this harmonization factor to harmonize the whole time series:

$\operatorname{GDP}_{\mathrm{h}}(y)=f_{\mathrm{h}} \cdot S(y)$

This amounts to using the scenario growth rates to extend the historical time series. For GHG emission data we phase out the harmonization factor $f_{\mathrm{h}}(y)$ linearly until a convergence year $y_{\mathrm{c}}=2050$. Thus, $f_{\mathrm{h}}\left(y_{\mathrm{h}}\right)=f_{\mathrm{h}}$ and $f_{\mathrm{h}}\left(y_{\mathrm{c}}\right)=1$, and linear interpolation between these values yields

$$
\begin{aligned}
E_{\mathrm{h}}(y) & =f_{\mathrm{h}}(y) E(y) \\
& =\left(\frac{\left(1-f_{\mathrm{h}}\right) y+\left(f_{h} y_{c}-y_{\mathrm{h}}\right)}{y_{\mathrm{c}}-y_{\mathrm{h}}}\right) E(y) .
\end{aligned}
$$

We phase out the harmonization factor to both keep the cumulative emissions of the scenario close to its design and achieve a smooth transition from historical emissions to scenario emissions. Scenarios where bunker emissions have not been removed before downscaling the post-2050 emissions include full bunker emissions.

Figure 5 shows the effect of harmonization on aggregate Kyoto GHG emissions for the five regions used for the RCPs. The harmonization factors are the same for all countries in a region, as the same historical data are used during the downscaling to calculate the initial emission intensities and for the harmonization during the combination of scenario data with historical data.

The harmonized SSPbe country data and downscaled SSPv2 data are combined with historical data such that historical data take precedence over scenario data where both are available. The last year with historical data is 2017. The combined time series are used in the downscaling process of emission data.

\subsection{Downscaling of RCP and SSPv2 emission data}

RCP and SSPv2 downscaling uses the IPAT-based convergence downscaling with exponential convergence of emission intensities as introduced in Sect. 2.3 for all gases and sectors. The parameters are the same for RCP and SSPv2. The convergence years are set for each SSP individually but with no regional variation. Convergence years are shown in Table 4.

For the RCPs we use the SSPbe country data as the downscaling key, while for SSPv2 we use the data from the scenarios downscaled to the country level (Sect. 4.3). 


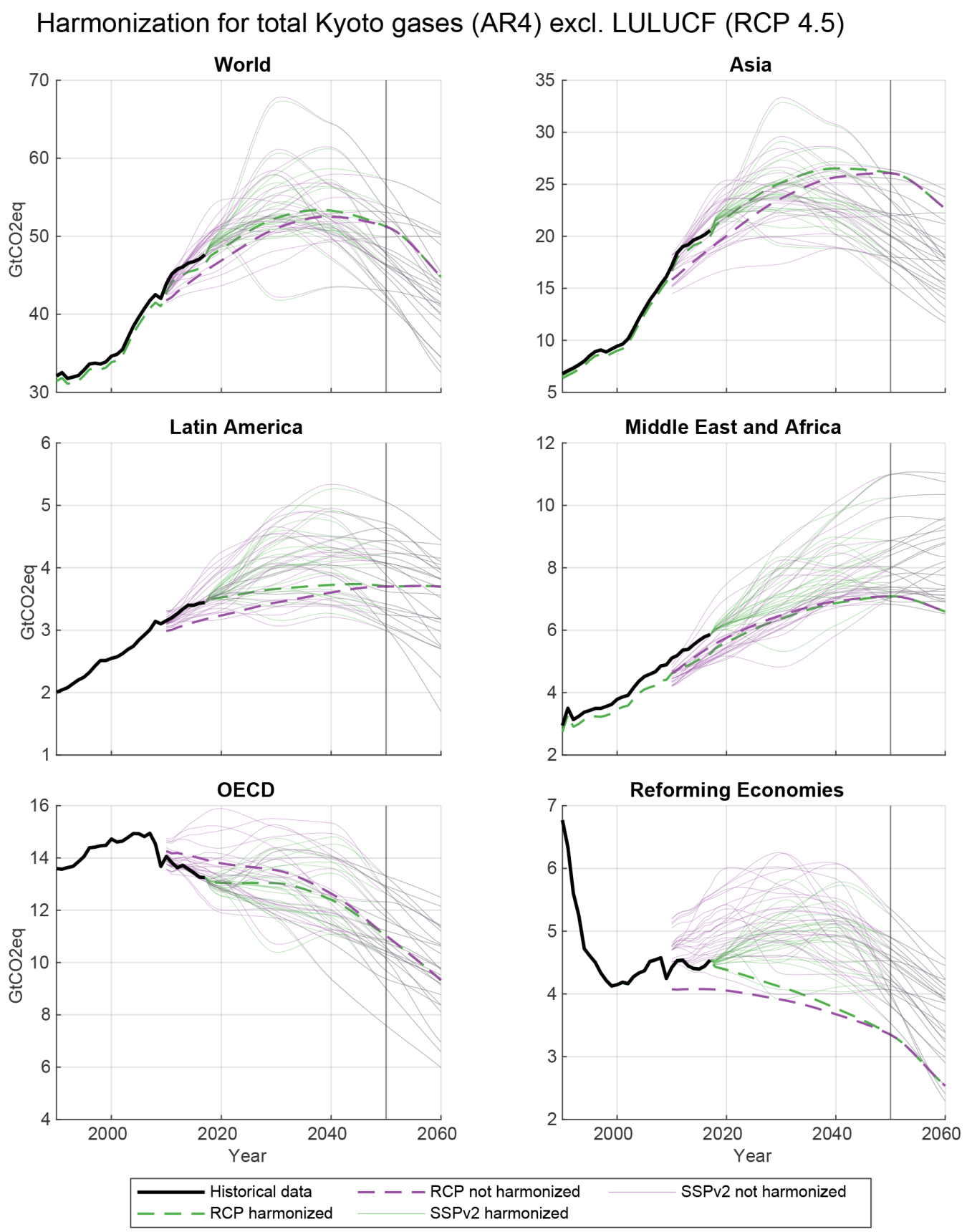

Figure 5. Harmonization of emission scenarios to historical data. The harmonization factor is phased out until 2050. The regions shown here are built from downscaled data to harmonize the region definitions of the SSPv2 scenarios to the RCP regions. As the region definitions of some IAMs do not cover all countries, the aggregate data are in some cases lower than the historical data (see, e.g., the Middle East and Africa region). Harmonization factors are similar for all RCPs, as the IAM groups use the same historical data for all their scenarios. Harmonization factors for individual gases, especially fluorinated gases, can be larger (or in the case of $\mathrm{CO}_{2} \mathrm{smaller}$ ). See Sect. S2.2 in the Supplement for details.

To illustrate the influence of the downscaling method on the results, we complement our standard results using IPAT downscaling with exponentially converging emission intensities (IE, see Sect. 2.3) with comparison datasets using IPAT downscaling with constant relative emission intensities (IC, see Appendix D1) and constant-share downscaling (CS, see Sect. 2.2 and Appendix D2), which is independent of the socio-economic scenarios.

We downscale each RCP-SSP combination from Table 2 for all three GDP country model groups (IIASA, PIK, and 
OECD) and each SSPv2 scenario from Table 1 for all available IAM implementations (see Appendix B1 for details). Each of these scenarios is available in two versions, one where the scenarios have been corrected for bunker emissions and one where they have not been corrected.

\subsection{Combination with historical data}

The downscaled RCP and downscaled SSPv2 data are combined with historical emission data such that historical data take precedence over scenario data where both are available. The last year with historical data is 2017. The scenario data are harmonized to interpolated 2017 historical data as described in Sect. 4.4.

\section{Results}

Here, we discuss and present the data for some key countries, selected from all five regions. From the Asia regions we selected China, Afghanistan, and South Korea to represent the diverse economical situations present in the region. Afghanistan is an extreme case not only in the Asia region but globally, as the SSP basic elements project very high GDP 3 growth rates (Fig. 6). From Latin America we select Brazil and Guatemala, which differ substantially in historical emission intensity and economical development under the SSPs. The Middle East and Africa region is represented by South Africa, a country with relatively high GDP per capita, and Ethiopia, with one of the world's lowest GDP per capita values but very high economical growth in recent years. For the OECD we selected three countries: two major world economies, the USA and the United Kingdom, which have high GDP per capita, with the USA having twice the UK's emissions per unit of GDP; the third country is Bulgaria, with roughly half of the UK's GDP per capita. The region of reforming economies is represented by its main economical power, Russia, and by Uzbekistan, which has a GDP per capita of less than one-third of the Russian GDP per capita. For these countries we present selected downscaled scenarios to highlight some of the factors influencing the downscaling results.

The final GDP scenarios are displayed in Figs. 6 and 7. The SSPv2d GDP pathways are very similar for all IAM groups, as they are all based on the same OECD country data. The SSPbe data from IIASA and PIK vary substantially from the OECD and SSPv2d data for several countries and scenarios.

Figures 8 and 9 show the resulting country pathways for RCP2.6, aggregate Kyoto GHGs, and IPAT downscaling with exponential convergence. Results for individual gases and all RCPs can be found in Sect. S2.4 in the Supplement. Figures 10 and 11 compare the exponential IPAT results with

\footnotetext{
${ }^{3}$ All references to GDP in this section are referencing purchasing-power-parity-adjusted (PPP-adjusted) GDP.
}

other downscaling methods for RCP2.6 and SSP2. Results for individual gases and an additional RCP-SSP combination (RCP6.0 and SSP5) can be found in Sect. S2.5 in the Supplement.

Influence of the socio-economic scenarios on downscaled emissions is high where the socio-economic scenarios and/or historical emission intensity are diverse within a region. Where they are similar, the resulting country emission pathways are similar. We have selected countries which differ in at least one of these indicators for the example plots shown, and consequently all regions show some differentiation. In relatively homogeneous regions like the OECD the differentiations are small and comparable to the spread of scenarios from different modeling groups, while for regions with large differences in historical emission intensity and/or GDP growth rates, the country pathways show strong variations. The most prominent example in the figures is Afghanistan, where high GDP growth and converging emission intensities lead to negative emissions in 2100, which are more than twice the current positive emissions. Relatively developed countries in the same region have much smaller negative emissions relative to current emission levels. We have to note here that this is a downscaling study, not an equity study. There is no implication of fairness in the resulting pathways.

The influence of the downscaling method is most prominent for regions with high economic differentiation as well. However, especially for the Asia region, the differences between methods are more visible than the differences between scenarios. The major influence of the GDP growth rates is clearly visible from Figs. 10 and 11: constant-share downscaling, which does not take the GDP scenarios into account, differs strongly from the other methods, which use GDP data. When comparing pathways with convergence (BIE) with pathways without convergence (BIC), the influence of convergence of emission intensities is visible as well but is less prominent.

Figures 12 and 13 show the influence of the correction of scenarios for bunker emissions on the example countries of the European Union (EU; Fig. 12) and Ethiopia (Fig. 13). As bunker emissions are distributed to the regions based on historical emission shares the influence is much larger for the EU than for Ethiopia. While the absolute emission difference is higher for high-emission scenarios, considering bunker emissions can be decisive for net-negative or net-positive emissions in high-mitigation scenarios (Fig. 12). Figures for the other example countries can be found in Sect. S2.6 in the Supplement.

\section{Discussion and limitations}

The main challenge for a downscaling methodology is to produce sensible results in regions with diverse economical situations, especially in scenarios with strongly decreasing or even negative emissions. The established IPAT method with 


\section{RCPd/SSPbe and SSPv2d PPP adjusted GDP scenarios}
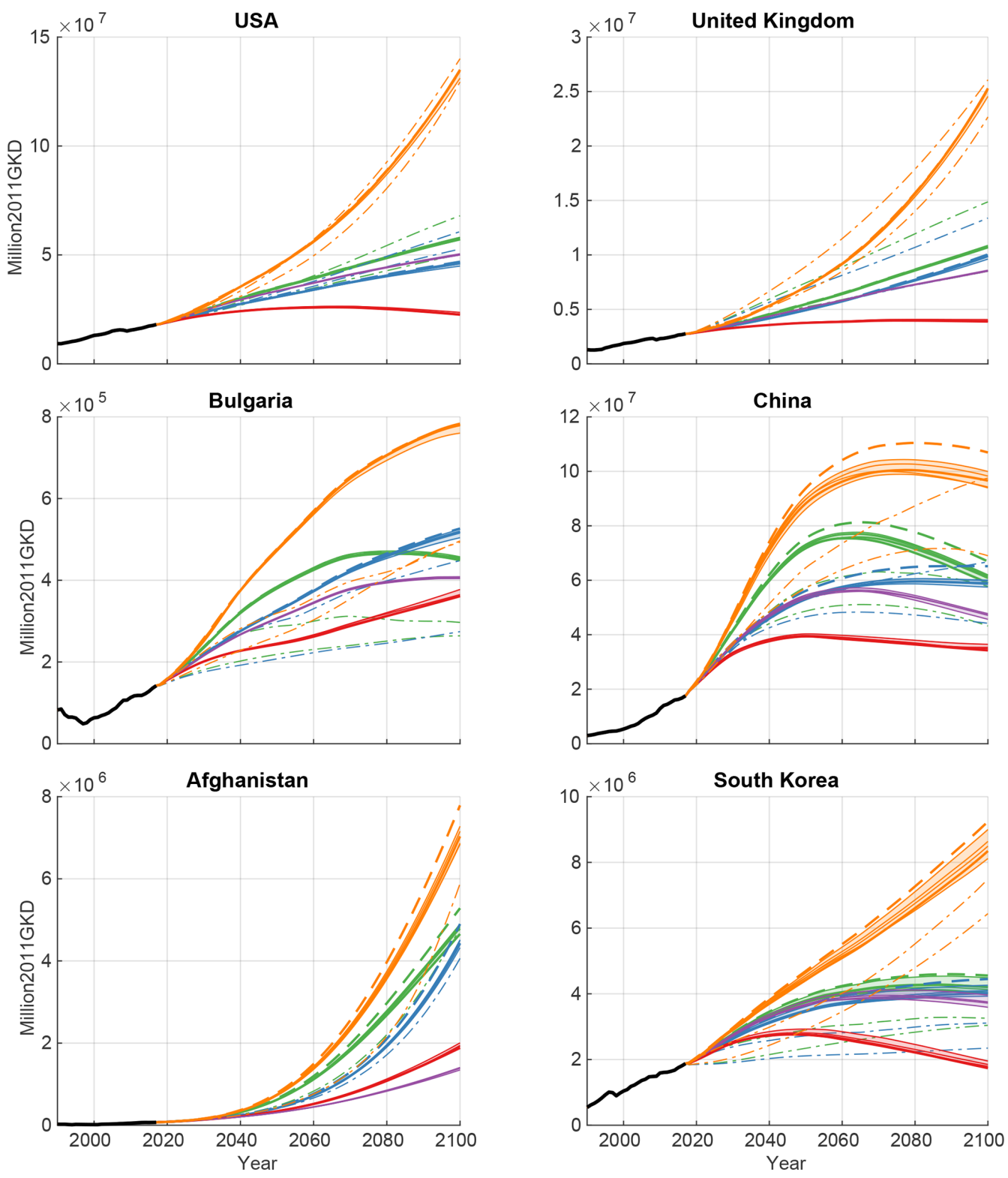

\begin{tabular}{|c|c|c|c|}
\hline $\begin{array}{c}\text { Historical data } \\
\text { SSP1 } \\
\text { SSP2 }\end{array}$ & $\begin{array}{r}\text { SSP3 } \\
\text { SSP4 } \\
\text { SSP5 }\end{array}$ & $\begin{array}{c}\text { SSPV2d marker scen. } \\
\text { SSPV2d scenario } \\
\text { SSPV2d range }\end{array}$ & $\begin{array}{l}---\mathrm{RCPd} / \mathrm{SSPbe}(\mathrm{OECD}) \\
---\mathrm{RCPd} / \mathrm{SSPbe}(\mathrm{PIK} / \| \mathrm{ISA})\end{array}$ \\
\hline
\end{tabular}

Figure 6. GDP projections for all SSPs (basic elements and downscaled SSPv2). All scenarios harmonized to historical values. Countries from the regions of the OECD and Asia. The SSP-basic-elements data from PIK and IIASA vary substantially from the OECD data, and the OECD-based SSPv2 data vary for some countries and SSPs. GDP growth varies substantially between scenarios.

exponential convergence does not work for numerical reasons and is problematic because it produces early negative emissions for countries with low historical emission intensities, no matter if this is due to poverty or low-emission technologies. We opted to converge emission intensities before the transition to negative emissions, which alters the concept of convergence. Generally, a downscaling process al- ways needs several assumptions that influence the final data. These assumptions impact both downscaling results and results of studies based on the downscaled data. Thus, downscaled data also have to be used with caution and while keeping the assumptions made in mind. In the following, we list the main limitations of our approach and their impacts on the resulting emission pathways. 


\section{RCPd/SSPbe and SSPv2d PPP adjusted GDP scenarios}
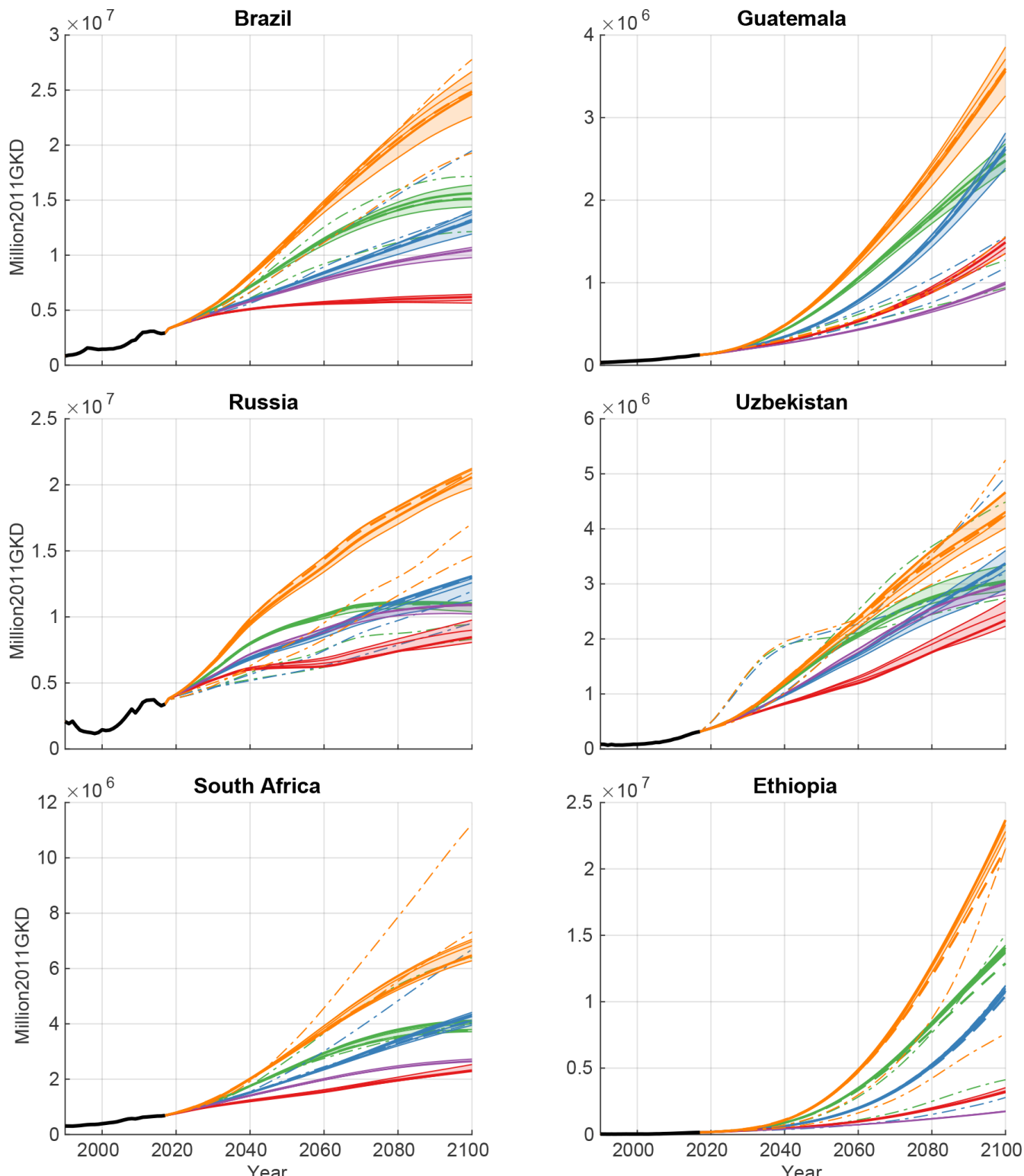

\begin{tabular}{|crcc|}
\hline Historical data & SSP3 & SSPv2d marker scen. & $---\mathrm{RCPd} / \mathrm{SSPbe}$ (OECD) \\
\cline { 2 - 3 } SSP1 & SSP4 & SSPv2d scenario & $----\mathrm{RCPd} / \mathrm{SSPbe}$ (PIK/IIASA) \\
\cline { 2 - 3 } SSP2 & SSP5 & SSPv2d range & \\
\cline { 2 - 3 } & &
\end{tabular}

Figure 7. GDP projections for all SSPs (basic elements and downscaled SSPv2). All scenarios harmonized to historical values. Countries from the regions of Latin America, reforming economies, and the Middle East and Africa. The SSP-basic-elements data from PIK and IIASA vary substantially from the OECD data and the OECD-based SSPv2 data for some countries and SSPs.

The choice of methodology is obviously a main driver of the downscaling results (Figs. 10 and 11). We chose the IPATbased convergence downscaling (Sect. 2.3) as the methodology for the main dataset but also offer downscaled data using the IPAT equation and constant relative emission intensities (Appendix D1) as well as simple constant-share downscaling (Sect. D2) for reference.
In all cases, the convergence method (Sect. 2.3) assumes at least partial convergence of emission intensities within a region. There is not much literature on the convergence of emission intensity of the GDP, while for the energy intensity of the GDP studies exist (Liddle, 2010; Markandya et al., 2006). The energy sector is a main driver of greenhouse gas emissions for most countries, and therefore energy intensity 


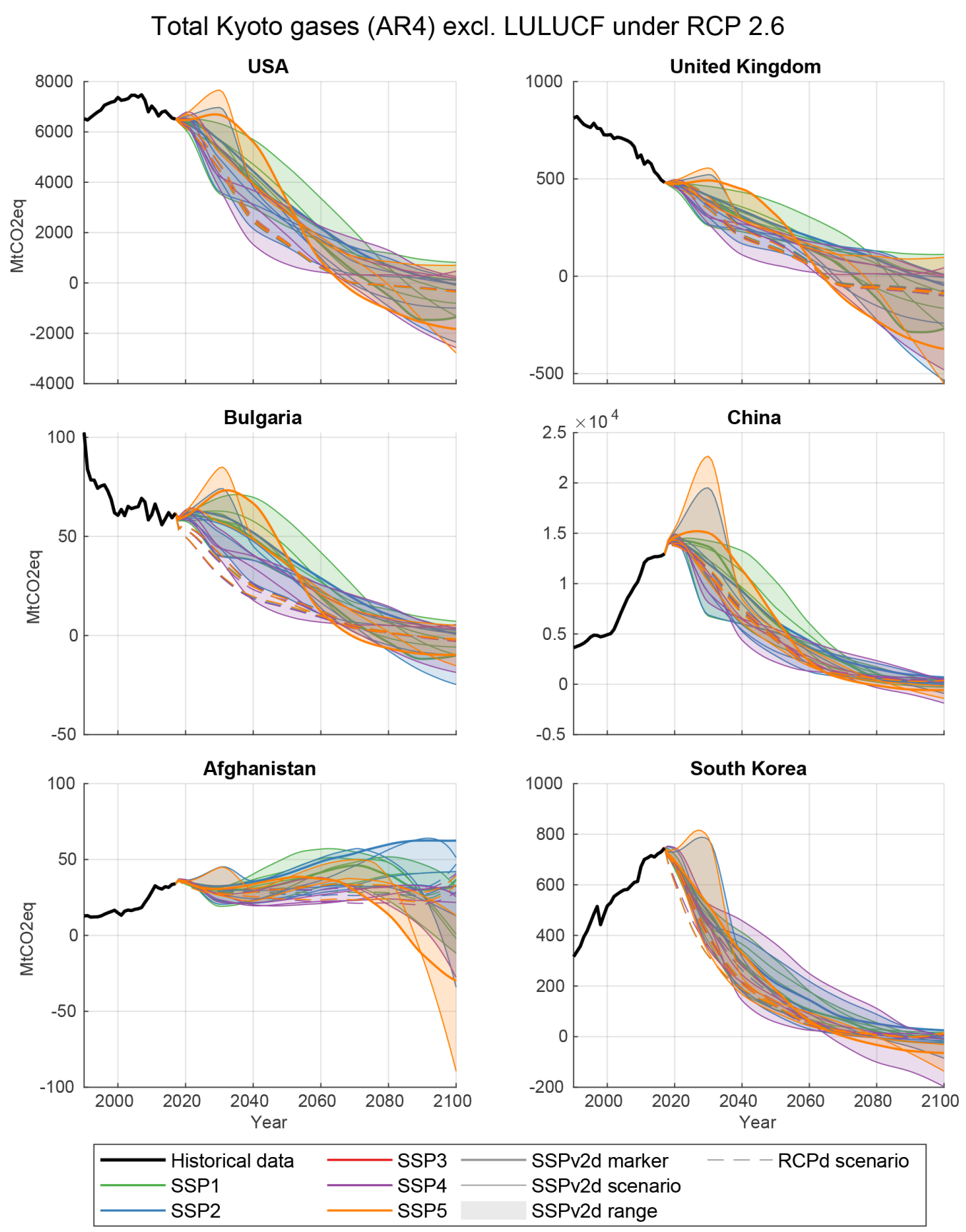

Figure 8. Results for RCP2.6 and all SSPs for both the RCPd and SSPv2d scenarios. Countries from the regions of the OECD and Asia. For the OECD region the differences in country pathways are driven by differences in regional pathways, not by the socio-economic development leading to very similar pathways for the countries in the region. In the Asia region the socio-economic development is more diverse and strongly influences the resulting country emission pathways. The most prominent example is the high negative emissions for Afghanistan in SSP5 driven by the very high GDP growth rates (Fig. 6). Note that South Korea is in the OECD region for the WITCH-GLOBIOM model.

of the GDP is a major input to the emission intensity of the GDP. Historical data show that the energy intensity often converges within regions (Markandya et al., 2006); however, this is not true for all regions (Liddle, 2010).

Several studies deal with the convergence of per capita $\mathrm{CO}_{2}$ emissions and come to different conclusions: Stegman and McKibbin (2005) find that when a large cross section of countries is considered there is little evidence for convergence, while there is some evidence of convergence within the OECD region. This is generalized by Panopoulou and Pantelidis (2009), who find that convergence to different per capita emission levels exist, a concept they call club con- 


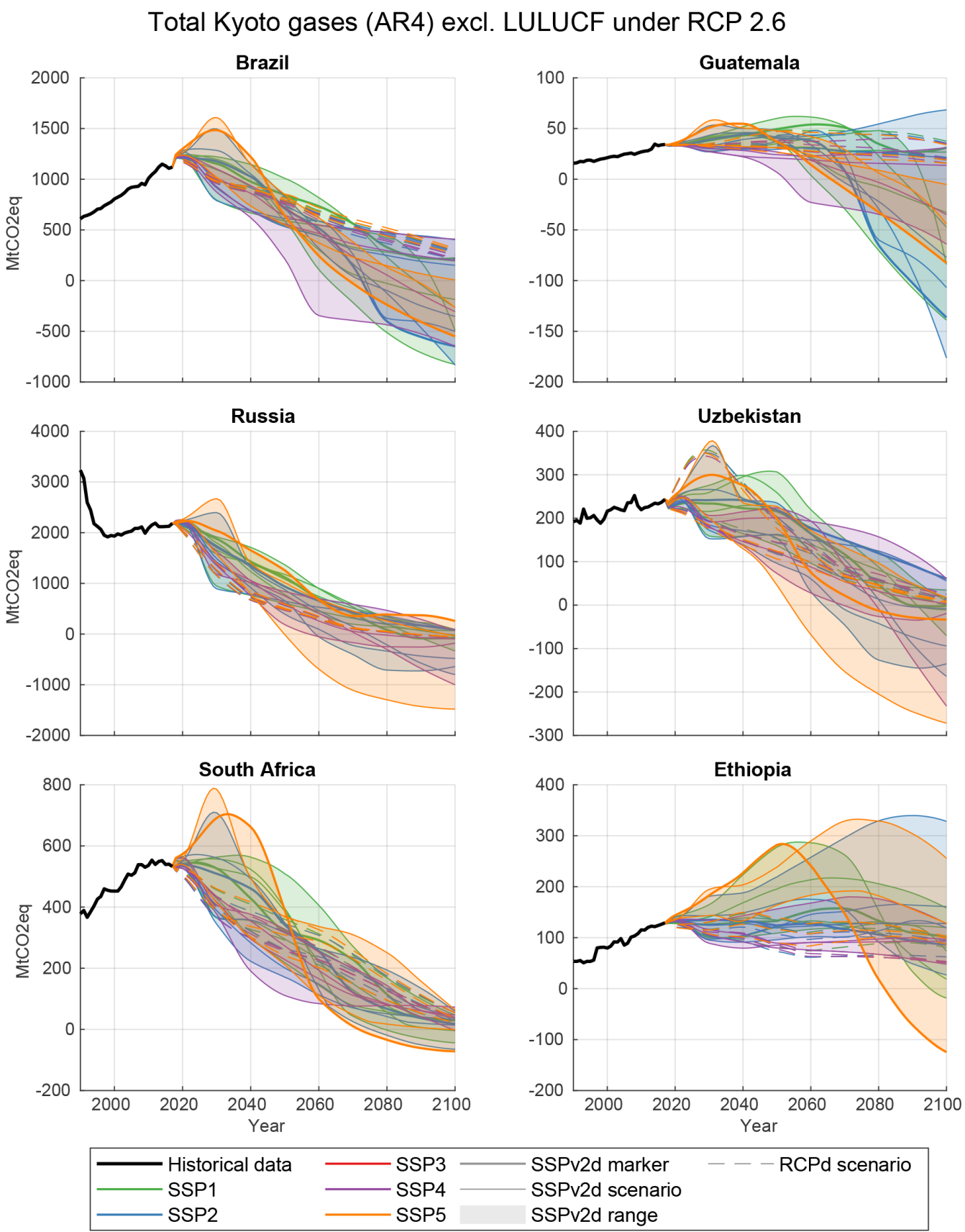

Figure 9. Results for RCP2.6 and all SSPs for both the RCPd and SSPv2d scenarios. Countries from the regions of Latin America, reforming economies, and the Middle East and Africa. All regions show strong influences of the diverse GDP growth projections (Fig. 7) within the regions.

vergence. Strazicich and List (2003) find that per capita $\mathrm{CO}_{2}$ emission levels have converged among 21 industrialized countries, which is confirmed by Romero-Ávila (2008), Jobert et al. (2010), and Chang and Lee (2008). Ordás Criado and Grether (2011) study 166 countries and find convergence within groups of countries (similar income, neighboring, institutional partners) between 1980 and 2000, especially within the EU and OECD regions.
This shows that convergence of emission intensities within regions is a sensible assumption, but it is important to note that it is an input to the downscaling process, and thus the emission intensities of the downscaled data are an input to and not a result of the process.

As a regional transition to negative emissions and negative emission intensities has not yet been observed, there is no evidence if convergence is a sensible assumption for pathways 


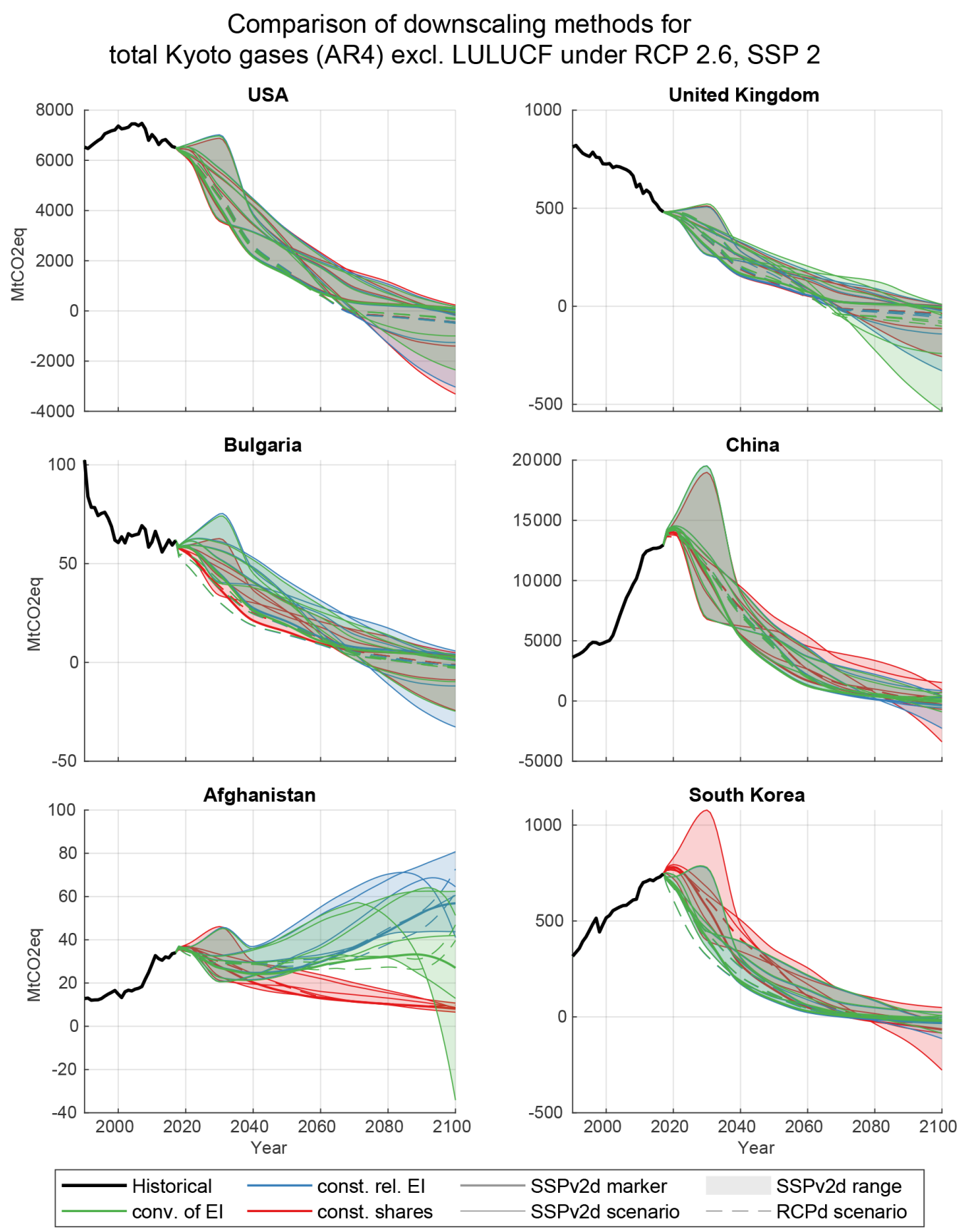

Figure 10. Influence of the downscaling method on country emissions for RCP2.6 and SSP2. Ranges are calculated over all IAM implementations in SSPv2d. RCPd scenarios are shown as individual lines only (dashed). For the OECD region the influence of the downscaling method is comparable to the influence of the IAM modeling group but with a clear influence of high GDP growth on emissions in the second half of the century. Countries in the Asia region have a more diverse GDP development (Fig. 6) and show a much stronger influence of the downscaling method.

with negative emissions. It is not yet clear which technologies will be used to achieve negative emissions. While for some technologies (e.g., direct air capture) a relation to GDP seems sensible; other technologies like BECCS also depend on national circumstances such as the availability of land to grow energy crops and safe storage options for the captured $\mathrm{CO}_{2}$.

More generally, the downscaling methodology considers the emission intensity per country and gas but does not consider the reasons for high and low emission intensities. Thus, if a region contains two countries with similar emission in- 


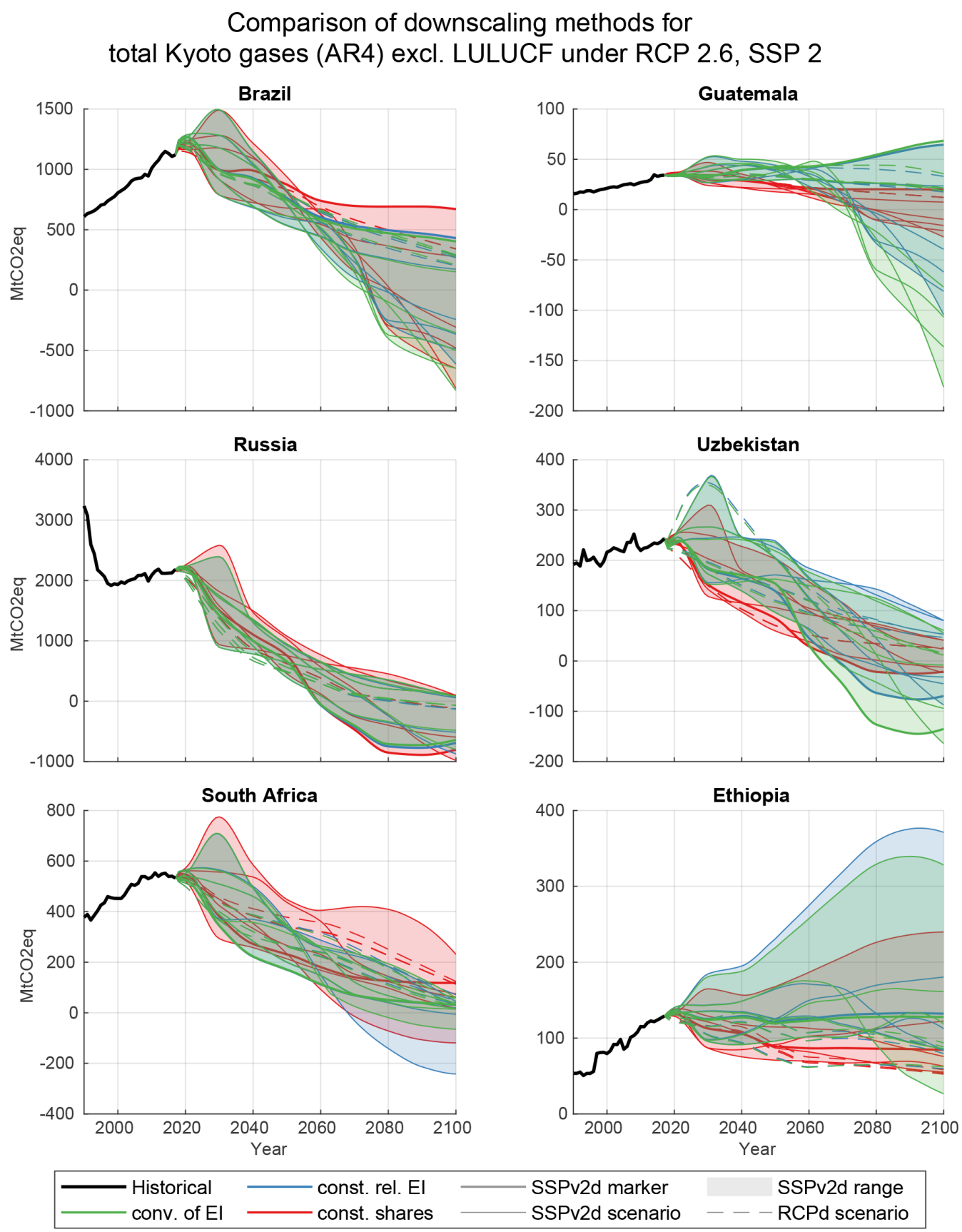

Figure 11. Influence of the downscaling method on country emissions for RCP2.6 and SSP2. Ranges are calculated over all IAM implementations in SSPv2d. RCPd scenarios are shown as individual lines only (dashed). For the Latin America region the influence is comparable to the OECD region and mainly visible in the second half of the century (top panels). The Middle East and Africa region shows a strong influence of the downscaling method (bottom panels).

tensities in the harmonization period, the algorithm will create similar emission intensity pathways for both countries neither considering if, e.g., a low emission intensity comes from a low development level or a high share of renewables nor considering the potential for mitigation technologies (e.g., for BECCS). As our analysis is carried out on national total emissions per gas, it is also not taken into account if, e.g., high methane emissions come from agriculture or fugitive emissions from fossil fuel production and handling, which are easier to mitigate than agricultural emissions.

The SSP-basic-elements results assume very high GDP growth for several developing countries. For Afghanistan the GDP values for 2100 are between roughly 16 (SSP4) and over 110 (SSP5) times the 2015 value, to give one of the 


\section{Bunkers influence for European Union (28) total Kyoto gases (AR4) excl. LULUCF}
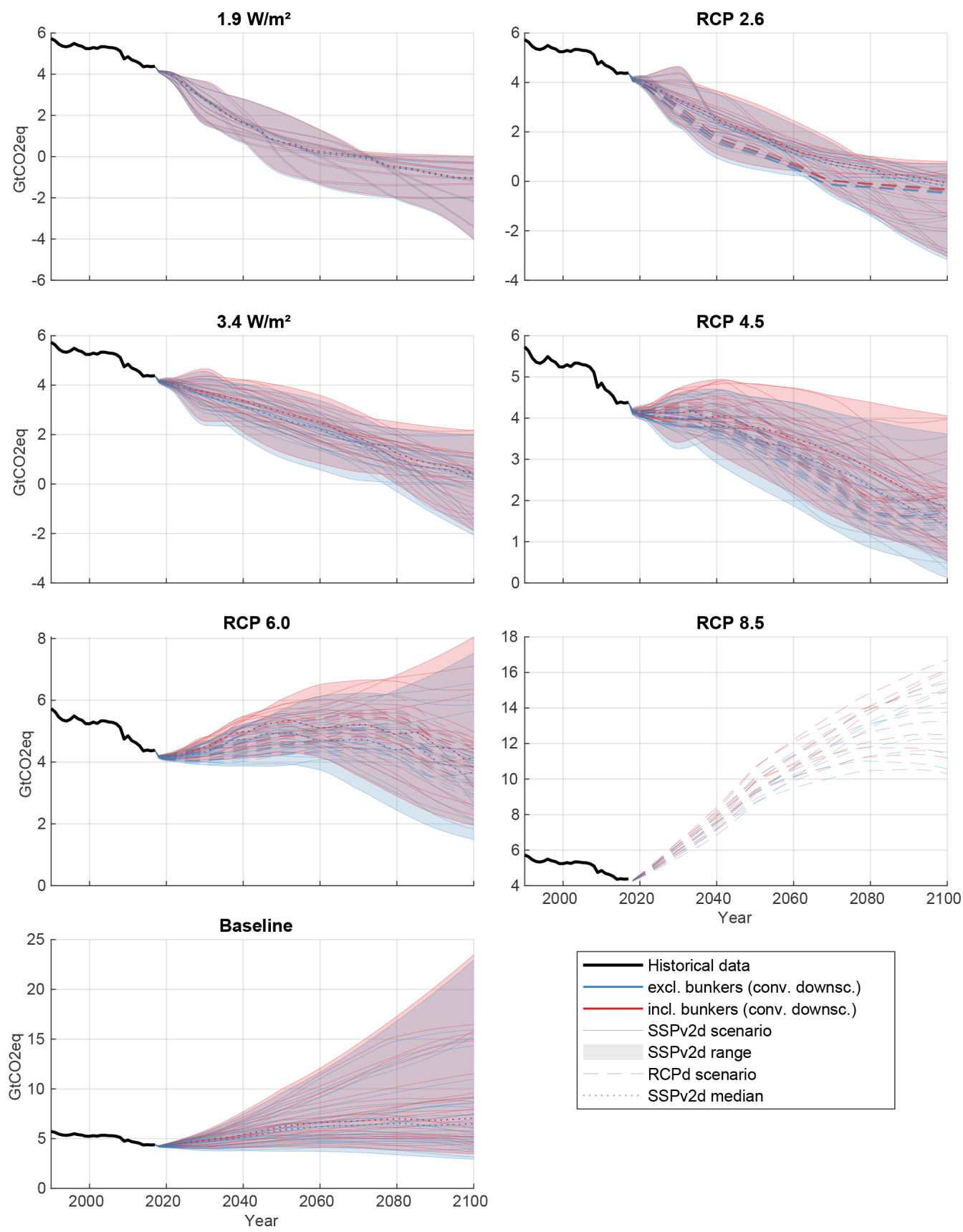

Figure 12. Influence of bunker emissions on results for the European Union. Ranges and the median are calculated over all SSPs and all IAM implementations in SSPv2d for each RCP. RCPd scenarios are shown as individual lines only (dashed). Absolute bunker emissions are high for higher emission scenarios; however, for low-emission scenarios bunker emissions can make the difference between net-negative and net-positive emissions.

most extreme examples. Countries in the same region that are more developed do not exhibit these kind of growth rates. With (relative) GDP being a driver of emissions in the downscaling model, emissions increase accordingly by a large factor or - in the case of strong mitigation pathways - decrease to minus several $100 \%$ of the 2015 emissions. The resulting absolute emission pathways seem highly unrealistic but are merely a result of the strong GDP growth in the SSP-basicelements results. 


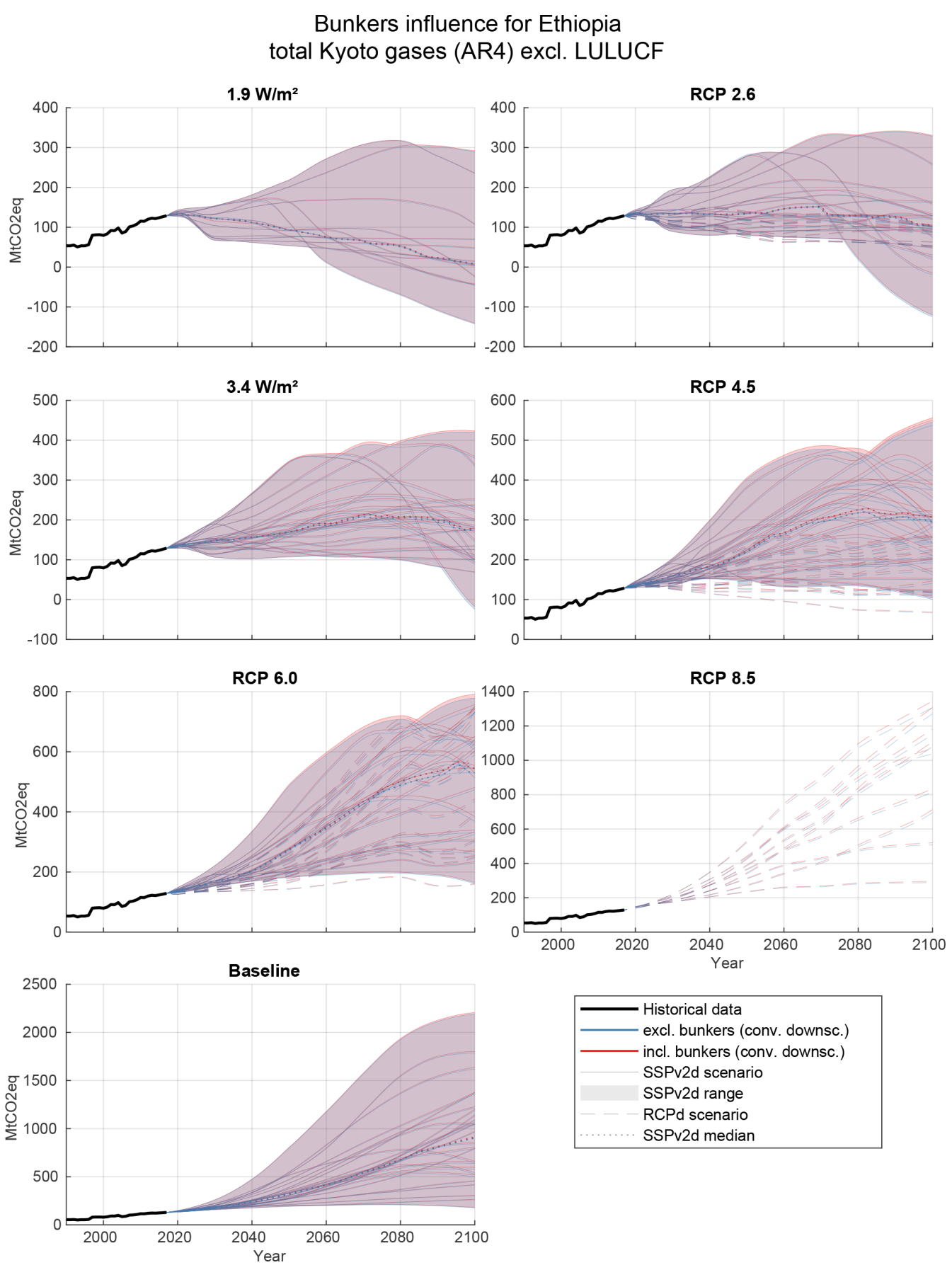

Figure 13. Influence of bunker emissions on results for Ethiopia. Ranges and the median are calculated over all SSPs and all IAM implementations in SSPv2d for each RCP. RCPd scenarios are shown as individual lines only (dashed). Generally the influence of bunker emissions is much smaller than for the EU, because the global bunker scenario is split into regions using historical shares which are high for the OECD and REF regions (EU) and low for the Africa region compared with future emission.

There are several sources for uncertainty in the data presented here, e.g., the uncertainty in historical emissions and GDP data. But the most important source of uncertainty is that we are using scenarios that project GDP and emission development 90 years into the future under given broad storylines. These scenarios are based on several assumptions and can only model idealized economical and technological developments. Some of the scenarios use technologies not yet proven to be applicable on a large scale (BECCS) and technologies deemed too dangerous to be used by several countries (nuclear), assume that we solve the problem of high variability in availability of renewable energy sources, 
et cetera. On the other hand the models cannot anticipate new and still unknown technologies, which might solve the problem in ways not imaginable today. Furthermore, the emission reductions in IAMs mainly come from technological change in energy production. The energy intensity of the GDP is very similar between baseline and mitigation scenarios (see, e.g., Fig. 3 of Peters et al., 2017). Thus, an important possibility for emission reduction - the reduction of energy use - is only considered partly by IAM scenarios. The underlying population and GDP projections do not model crises such as the 2008 financial crisis or the 2020 global COVID-19 (coronavirus disease 2019) pandemic and their impact on lives and the economy.

Most IAM scenarios have been created using some kind of cost optimization routine and therefore assume costs to be the driving factor of economic decision making - just steered by parameters such as a carbon tax or an emission cap. They thus assume an idealized version of the current economical system where cost-optimal decisions are made on a rational basis.

Essentially, IAM scenarios assume no revolutionary changes (be it of technological or societal nature) but rather a continuation of our current system with some modifications to reduce GHG emissions. While IAMs are one of the main tools to generate and assess socio-economic scenarios to mitigate climate change, their usefulness is not undisputed in the scientific community (see, e.g., Jewell and Anderson, 2019). Whenever the country-level scenarios presented here are used, the limitations and assumptions of the downscaling process as well as the underlying models have to be taken into account.

\section{Data availability}

All datasets produced for this paper are available for download at https://doi.org/10.5281/zenodo.3638137 (Gütschow et al., 2020). Each dataset comes in a csv (commaseparated value) file. The filename is constructed as follows: $<$ Source $><$ Bunkers $><$ Downscaling $>$.

The $<$ Source $>$ flag indicates which input scenarios were used:

- PMRCP (RCP scenarios downscaled using the SSPbe data): emission and socio-economic data, with scenarios being available as both harmonized to historical data and non-harmonized;

- PMSSP (downscaled SSPv2 scenarios): emission and socio-economic data, with scenarios being available as both harmonized to historical data and non-harmonized.

The $<$ Bunkers $>$ flag indicates if the input emission scenarios have been corrected for bunker emissions before downscaling to the country level or not. The flag is " $\mathrm{B}$ " for scenarios where emissions from bunkers have been removed before downscaling and "' (empty) where they have not been removed. We recommend using datasets where bunker emissions have been removed before downscaling.

The $<$ Downscaling $>$ flag indicates the downscaling technique used:

- IE: convergence downscaling with exponential convergence of emission intensities and convergence before transition to negative emissions (see Sect. 2.3, default downscaling method);

- IC: growth rates of regional emission intensity for all countries (see Appendix D1);

- CS: constant emission shares as a reference case independent of the socio-economic scenario (see Appendix D2).

All files contain data for all countries and variables for all scenarios (RCPd or SSPv2d), both harmonized and nonharmonized.

We recommend the use of the "BIE" dataset as a default.

More information on the data structure of the files is a available in the data description in the data repository (Gütschow et al., 2020).

\section{Conclusions}

The country-resolved downscaled RCP and downscaled SSPv2 scenarios we present here allow for climate policy analysis in terms of RCP GHG forcing scenarios and SSP socio-economic storylines on a per country basis. While we treat the "IE" method with converging emission intensities as our main dataset and use the others for reference, users can opt for more conservative assumptions using the datasets which employ of constant-share (CS) and constant-relativeemission-intensity (IC) downscaling. Earlier versions of the scenarios presented here have been used in several studies (Meinshausen et al., 2015; Robiou du Pont et al., 2016; du Pont et al., 2016; Robiou du Pont and Meinshausen, 2018) and are used by the climate policy assessment of the Climate Action Tracker (CAT; Climate Analytics and New Climate Institute, 2020). With this paper we make the data publicly available and describe the used methodology in detail. We hope that this enables a broader use of the data. 


\section{Appendix A: Definitions and acronyms}

In the Appendix we provide tables with lists of all acronyms and definitions used in the paper. Acronyms regarding the naming of downscaled data and files containing the data are described in Sect. 7. Greenhouse-gas-related acronyms are listed in Table A1; acronyms related to integrated assessment models are in Table A2; and RCP-SSP-related acronyms are in Table A3. Downscaling methods are listed in Table A4, and economical acronyms are in Table A5. Table A6 lists acronyms referring to institutions, and finally Table A7 explains the miscellaneous acronyms.

Table A1. Greenhouse-gas-related acronyms.

\begin{tabular}{|c|c|}
\hline Acronym & Description \\
\hline GHG & Greenhouse gas \\
\hline $\begin{array}{l}\text { Kyoto green- } \\
\text { house gases } \\
\text { (Kyoto GHGs) }\end{array}$ & GHGs included in the Kyoto protocol: $\mathrm{CO}_{2}, \mathrm{CH}_{4}, \mathrm{~N}_{2} \mathrm{O}, \mathrm{HFCs}, \mathrm{PFCs}, \mathrm{SF}_{6}$, and $\mathrm{NF}_{3}$ \\
\hline HFCs & $\begin{array}{l}\text { Hydrofluorocarbons: a group of GHGs consisting of hydrogen, carbon, and fluorine atoms that are used in } \\
\text { refrigerators and air conditioning }\end{array}$ \\
\hline PFCs & $\begin{array}{l}\text { (Per-)fluorocarbons: a group of GHGs consisting of carbon and fluorine atoms which have several industrial } \\
\text { and medical applications }\end{array}$ \\
\hline GWP & $\begin{array}{l}\text { Global warming potential: factor used to calculate an amount of } \mathrm{CO}_{2} \text { that would produce the same warming } \\
\text { as a quantity of a given GHG over a certain period of time, which is used here to refer to } 100 \text {-year potentials } \\
\text { according to a specified IPCC assessment report (see below) }\end{array}$ \\
\hline SAR & IPCC's “Second Assessment Report” (Houghton et al., 1996) \\
\hline AR4 & IPCC's “Fourth Assessment Report” (Landman, 2010) \\
\hline LULUCF & $\begin{array}{l}\text { Land use, land use change, and forestry: GHG emissions from this sector are subject to high annual fluctu- } \\
\text { ations and reporting uncertainties and can be negative, which are excluded from the downscaled dataset }\end{array}$ \\
\hline BECCS & $\begin{array}{l}\text { Bio-energy with carbon capture and storage: a technology to achieve "negative emissions", i.e., removing } \\
\mathrm{CO}_{2} \text { from the atmosphere through the use of bio-energy with subsequent } \mathrm{CO}_{2} \text { sequestration and long-term } \\
\text { storage }\end{array}$ \\
\hline
\end{tabular}


Table A2. Integrated assessment model (IAM) acronyms used in this paper.

\begin{tabular}{ll}
\hline Acronym & Description \\
\hline IAM & $\begin{array}{l}\text { Integrated assessment model: numerical model or coupled models to calculate scenarios of future eco- } \\
\text { nomical, technological, and ecological development under certain assumptions or boundary conditions }\end{array}$ \\
\hline AIM/CGE & Asia-Pacific Integrated Model/Computable General Equilibrium \\
\hline GCAM4 & Global Change Analysis Model \\
\hline IMAGE & Integrated Model to Assess the Global Environment \\
\hline MESSAGE-GLOBIOM & $\begin{array}{l}\text { Combination of the MESSAGE (Model for Energy Supply Strategy Alternatives and their General } \\
\text { Environmental Impact) energy model with the GLOBIOM (GLObal BIOsphere Model) and further } \\
\text { models }\end{array}$ \\
\hline REMIND-MAgPIE & $\begin{array}{l}\text { Combination of the REMIND (Regional Model of Investment and Development) economical model } \\
\text { with the MAgPIE (Model of Agricultural Production and its Impacts on the Environment) agricultural } \\
\text { model }\end{array}$ \\
\hline WITCH-GLOBIOM & $\begin{array}{l}\text { Combination of the WITCH (World Induced Technical Change Hybrid) economical model with GLO- } \\
\text { BIOM (GLObal BIOsphere Model) }\end{array}$ \\
\hline
\end{tabular}

Table A3. RCP-SSP-related acronyms.

\begin{tabular}{ll}
\hline Acronym & Description \\
\hline RCPs & $\begin{array}{l}\text { Representative Concentration Pathways: a set of scenarios of future GHG concentrations used to drive climate } \\
\text { models in comparison studies for which several derivative products, e.g., compatible emission scenarios, exist }\end{array}$ \\
\hline RCPd & Downscaled RCP emission scenarios \\
\hline SSPs & $\begin{array}{l}\text { Shared Socio-economic Pathways: a set of five socio-economic storylines to be used for different types of } \\
\text { studies }\end{array}$ \\
\hline SSPbe & SSP basic elements: first numerical quantifications of the SSP storylines \\
\hline SSPv2 & Version 2 of the IAM SSP scenario quantifications \\
\hline SSPv2d & Downscaled SSPv2 scenarios \\
\hline SSPCMIP6 & $\begin{array}{l}\text { IAM SSP scenario quantifications created for CMIP6, which higher detail in emission categories but are limited } \\
\text { in RCP-SSP combinations and modeling groups }\end{array}$ \\
\hline SSPDB & SSP scenario database hosted at IIASA \\
\hline RCP-SSP & Combination of an RCP forcing scenario with an SSP storyline \\
\hline SRES & $\begin{array}{l}\text { The IPCC's "Special Report on Emissions Scenarios" on future socio-economic and emission scenarios, which } \\
\text { is used here to refer to the scenarios created for the report }\end{array}$ \\
\hline
\end{tabular}

Table A4. Downscaling methods.

\begin{tabular}{ll}
\hline Acronym & Description \\
\hline IE & $\begin{array}{l}\text { Convergence downscaling with exponential convergence of emission intensities and convergence before transi- } \\
\text { tion to negative emissions (see Sect. 2.3, default downscaling method) }\end{array}$ \\
\hline IC & Growth rates of regional emission intensity for all countries (see Appendix D1) \\
\hline CS & Constant emission shares as a reference case independent of the socio-economic scenario (see Appendix D2) \\
\hline
\end{tabular}


Table A5. Economical acronyms.

\begin{tabular}{ll}
\hline Acronym & Description \\
\hline GDP & Gross domestic product \\
\hline IPAT & $\begin{array}{l}\text { The IPAT equation states that impact }(I) \text { equals population }(P) \text { multiplied by affluence }(A) \text { and a technology } \\
\text { factor }(T)\end{array}$ \\
\hline EI & Emissions intensity of the GDP (emissions per unit of GDP) \\
\hline PPP & $\begin{array}{l}\text { Purchasing power parity: a special form to calculate the GDP where comparison between countries is not via } \\
\text { market exchange rates but via the price of a representative basket of goods }\end{array}$ \\
\hline GKD & Geary-Khamis dollar (international dollar): currency unit for PPP-adjusted GDP \\
\hline
\end{tabular}

Table A6. Acronyms for institutions.

\begin{tabular}{ll}
\hline Acronym & Description \\
\hline IIASA & International Institute for Applied Systems Analysis \\
IPCC & Intergovernmental Panel on Climate Change \\
OECD & Organisation for Economic Co-operation and Development \\
PIK & Potsdam Institute for Climate Impact Research \\
UNFCCC & United Nations Framework Convention on Climate Change \\
\hline
\end{tabular}

Table A7. Miscellaneous acronyms.

\begin{tabular}{ll}
\hline Acronym & Description \\
\hline CMIP6 & Coupled Model Intercomparison Project Phase 6 \\
PRIMAP & Potsdam Real-time Integrated Model for the probabilistic Assessment of emission Paths \\
MATCH & Modeling and Assessment of Contributions to Climate Change UNFCCC ad hoc group \\
CDIAC & Carbon Dioxide Information Analysis Center \\
WDIs & World Development Indicators: collection of socio-economic data published by the World Bank \\
HYDE & History Database of the Global Environment \\
\hline
\end{tabular}




\section{Appendix B: Scenario details}

\section{B1 SSPv2 scenarios}

Most IAMs have run all RCP-SSP combinations, but the highest and lowest RCP forcing levels were not attained by all models for all SSPs. Additionally some models have not simulated all SSPs. Table B1 gives an overview of the available models for each RCP-SSP combination.

Table B1. SSP IAM implementations available in the SSPv2 database. Model names are abbreviated using the first character. Illustrative marker scenarios are marked by bold italic letters. There are no RCP8.5 scenario implementations, as no SSP IAM baseline shows forcing levels above RCP8.5.

\begin{tabular}{|c|c|c|c|c|c|}
\hline & SSP1 & SSP2 & SSP3 & SSP4 & SSP5 \\
\hline Baseline & $\boldsymbol{I}, \mathrm{M}, \mathrm{A}, \mathrm{G}, \mathrm{R}, \mathrm{W}$ & $\mathrm{I}, \boldsymbol{M}, \mathrm{A}, \mathrm{G}, \mathrm{R}, \mathrm{W}$ & $\mathrm{I}, \mathrm{M}, \boldsymbol{A}, \mathrm{G}, \mathrm{W}$ & $\mathrm{I}, \mathrm{A}, \boldsymbol{G}, \mathrm{W}$ & I, A, G, $\boldsymbol{R}, \mathrm{W}$ \\
\hline RCP8.5 & - & - & - & - & - \\
\hline RCP6 & - & $\mathrm{I}, \boldsymbol{M}, \mathrm{A}, \mathrm{G}, \mathrm{R}, \mathrm{W}$ & $\mathrm{I}, \mathrm{M}, \boldsymbol{A}, \mathrm{W}$ & $\mathrm{I}, \boldsymbol{G}, \mathrm{W}$ & I, A, G, $R, \mathrm{~W}$ \\
\hline RCP4.5 & $\boldsymbol{I}, \mathrm{M}, \mathrm{A}, \mathrm{G}, \mathrm{R}, \mathrm{W}$ & $\mathrm{I}, \boldsymbol{M}, \mathrm{A}, \mathrm{G}, \mathrm{R}, \mathrm{W}$ & $\mathrm{I}, \mathrm{M}, \boldsymbol{A}, \mathrm{W}$ & $\mathrm{I}, \mathrm{A}, \boldsymbol{G}, \mathrm{W}$ & $\mathrm{I}, \mathrm{A}, \mathrm{G}, \boldsymbol{R}, \mathrm{W}$ \\
\hline $3.4 \mathrm{~W} \mathrm{~m}^{-2}$ & $I, \mathrm{M}, \mathrm{A}, \mathrm{G}, \mathrm{R}, \mathrm{W}$ & $\mathrm{I}, \boldsymbol{M}, \mathrm{A}, \mathrm{G}, \mathrm{R}, \mathrm{W}$ & $\mathrm{I}, \mathrm{M}, \boldsymbol{A}, \mathrm{W}$ & $\mathrm{I}, \mathrm{A}, \boldsymbol{G}, \mathrm{W}$ & $\mathrm{I}, \mathrm{A}, \mathrm{G}, \boldsymbol{R}, \mathrm{W}$ \\
\hline $\mathrm{RCP} 2.6$ & $\mathrm{I}, \mathrm{M}, \mathrm{A}, \mathrm{G}, \mathrm{R}, \mathrm{W}$ & $\mathrm{I}, \boldsymbol{M}, \mathrm{A}, \mathrm{G}, \mathrm{R}, \mathrm{W}$ & - & $\mathrm{I}, \mathrm{A}, \boldsymbol{G}, \mathrm{W}$ & $\mathrm{A}, \mathrm{G}, \boldsymbol{R}$ \\
\hline $1.9 \mathrm{~W} \mathrm{~m}^{-2}$ & $I, \mathrm{M}, \mathrm{A}, \mathrm{G}, \mathrm{R}, \mathrm{W}$ & $\mathrm{I}, \boldsymbol{M}, \mathrm{A}, \mathrm{G}, \mathrm{R}$ & - & $\mathrm{W}$ & $\mathrm{G}, \boldsymbol{R}$ \\
\hline Marker & IMAGE & MESSAGE & AIM/CGE & GCAM4 & REMIND \\
\hline
\end{tabular}




\section{Appendix C: Methodological details}

\section{C1 PPP conversion of SSP socio-economic data}

Recent historical GDP data in purchasing-power-paritycorrected (PPP-corrected) form uses the PPP data from the 2011 revision of the International Comparison Program (ICP, The World Bank, 2014). It is published in units of 2011 international dollars (Geary-Khamis dollar, GKD). Data in 2011 international dollars (GKD) are PPP-corrected using the $2011 \mathrm{ICP}$, and the exchange rate to the US dollar is set to be USD $1=$ GKD 1 (international dollars for 2011) in 2011. The SSP-basic-elements data are published in 2005 international dollars (GKD) and thus based on the 2005 ICP revision (The World Bank, 2008), making conversion between the two units necessary.

The conversion consists of two steps: all countries but the US have changed PPP factors that relate the country's purchasing power to the US purchasing power; additionally the purchasing power of the reference currency (USD) changed between the revisions, requiring a further correction. The World Development Indicators (WDIs, The World Bank, 2019b, a) provide PPP factors used to convert data in international dollars into local currency units (LCAs) for both 2005 (indicator PA.NUS.PPP.05, PPP05 for short) and 2011 (PA.NUS.PPP, PPP11 for short). These can be used to correct for the different PPP values. To correct for the reference currency we use the GDP inflation (indicator NY.GDP.DEFL.KD.ZG, INFL for short) for the US to correct for USD inflation. The full conversion is

$$
\begin{aligned}
& \mathrm{GDP}_{c}^{2011 \mathrm{GKD}}=\mathrm{GDP}_{c}^{2005 \mathrm{GKD}} \\
& \frac{\mathrm{PPP}^{2} 1_{c}}{\mathrm{PPP}_{c}} \prod_{y=2006}^{2011} \mathrm{INFL}_{\mathrm{USA}}(y) \text {, }
\end{aligned}
$$

for country $c$.

For some countries we have to make exceptions to this conversion rule. For Belarus and Mauritania the 2005 PPP factors are very high, leading to very high conversion factors and results in values not in line with historical GDP data in 2011 international dollars (GKD). For these countries we use the 2005 value given in the PPP11 time series. The same is done if the PPP05 factor is not available. This is the case for Aruba and Eswatini. If a country is not present in the PPP11 time series we use data from the Penn World Table version 9.1 (PWT; Feenstra et al., 2019, 2015). We multiply the market exchange rate (MER, "xr" in PWT) for the country with the price level of the GDP ("pl_gdpo" in PWT) to obtain a PPP time series. This is used for Djibouti and Syria. If no PPP data are available only the USD inflation is used. This is used for Cuba, French Polynesia, New Caledonia, Puerto Rico, and Somalia. For most of these countries no historical GDP PPP data are available.

This transformation is not strictly needed to create our dataset, as we only use the growth rates of the GDP PPP scenarios; however, the transformed time series give a good indication on how large the discrepancy between historical GDP PPP data and the scenario data is. Except for a few small countries the discrepancy is small.

\section{Appendix D: Methodological variants}

\section{D1 Downscaling with constant relative emission intensity}

To demonstrate the influence of convergence we also created a dataset in which the regional emission intensity growth rates are used for all countries of a region. To achieve that, the emission intensity is held constant at the value of the harmonization year for the temporary emission intensity pathway:

$\mathrm{EI}_{c}(y)=\mathrm{EI}_{c}\left(y_{\mathrm{h}}\right)$

See also Fig. D1.

While methodologically very similar to the exponential convergence downscaling, this is actually not convergence downscaling but a form of external-input-based downscaling.

\section{D2 Constant-share downscaling}

As a control case for the influence of socio-economic data on the downscaling we also created a dataset not using GDP data at all. We downscaled regional scenarios using historical country shares as

$S_{\mathcal{C}}\left(y_{0}\right)=E_{\mathcal{C}}\left(y_{0}\right) / E_{\mathbb{R}}\left(y_{0}\right)$

throughout the whole scenario timeframe. Emissions are calculated using

$E_{\mathcal{C}}=S_{\mathcal{C}}\left(y_{0}\right) E_{\mathbb{R}}$

\section{Appendix E: Region definitions}

For the RCPs we use the definitions of the R5 regions as presented on the RCP database website (IIASA, 2009). The SSPs use the updated R5.2 region definitions, which are available on the SSP database website (IIASA, 2018). However, the exact regions differ by IAM, as they have to be created from sums of native IAM regions which differ by IAM. We thus use model-specific region definitions based on an Excel document formerly available on the SSPDB website checked against (and slightly corrected by) the region definitions presented in the SSP model documentation (SSP, 2015). 


\section{Constant Relative Emissions Intensity Downscaling Example}

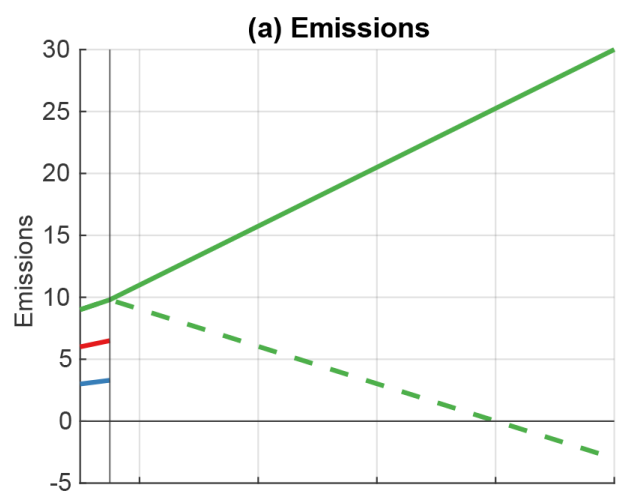

(c) Temporary Emissions Intensity

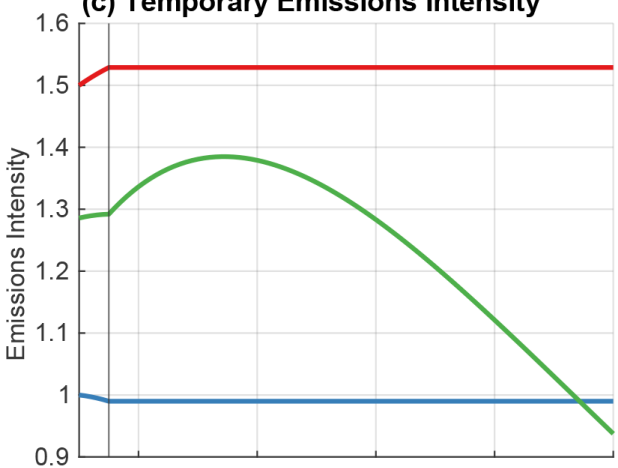

(e) Final Emissions

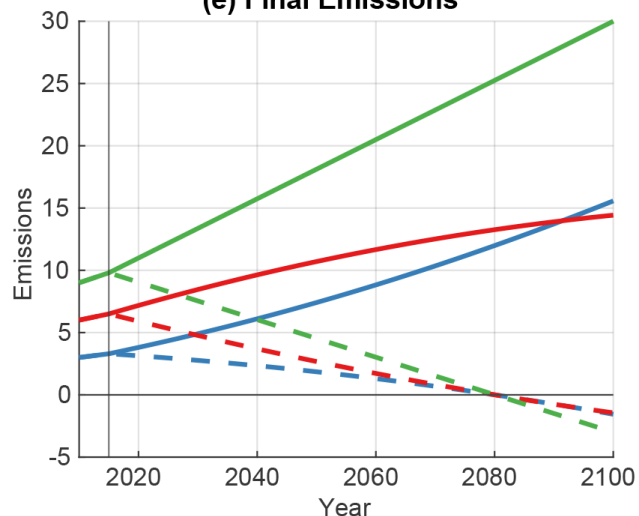

(b) GDP

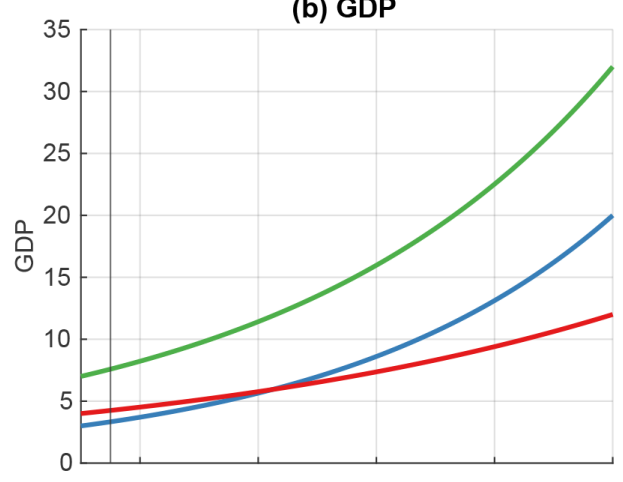

(d) Temporary Emissions

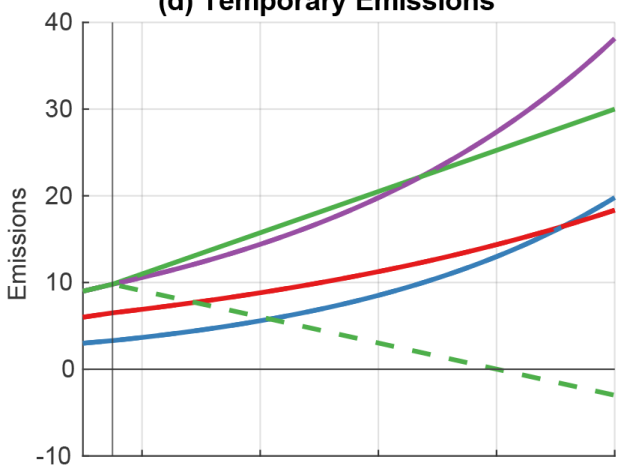

(f) Final Emissions Intensity

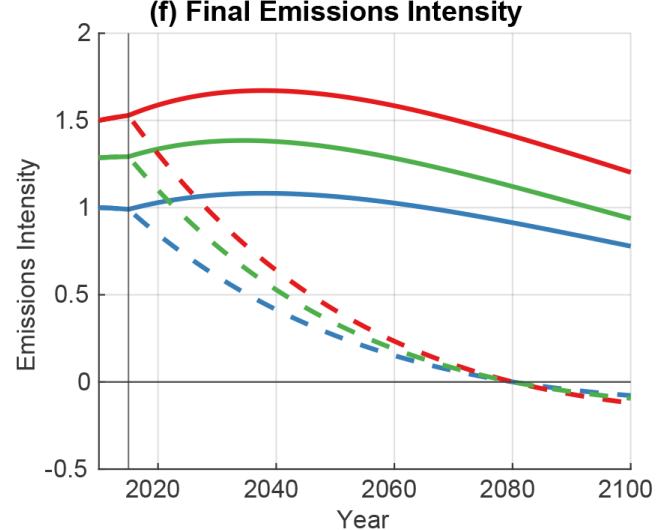

\begin{tabular}{|c|c|c|}
\hline Country 1 & $\begin{array}{l}\text { Region } \\
\text { Country Sum }\end{array}$ & $\begin{array}{l}- \text { No Negative Emissions } \\
-\ldots \text { Negative Emissions }\end{array}$ \\
\hline
\end{tabular}

Figure D1. Steps of external-input-based downscaling of regional emission data using the IPAT equation and country GDP data explained using a two-country region. We use the assumption of constant relative emission intensities to enable the use of GDP as an external input for emission downscaling. Regional emission data are given for the whole time period, while for the countries only historical data are available (a). GDP data are given for both countries and the region (b) for the whole time period. In the first step temporary emission intensity pathways for the countries are calculated using a constant extrapolation of historical values (2015) (c). Multiplication with the given GDP time series creates temporary emission time series. These do not sum up to the regional value (see d) and have to be scaled to the regional value (results in e). This also changes the emission intensities (f). 
Supplement. The supplement related to this article is available online at: https://doi.org/10.5194/essd-13-1005-2021-supplement.

Author contributions. JG designed the study, carried out the downscaling process, and led the paper-writing process. All authors discussed the methodology and results and contributed to the paper.

Competing interests. The authors declare that they have no conflict of interest.

Financial support. This research has been supported by the German Federal Ministry for the Environment, Nature Conservation and Nuclear Safety (grant no. 16_II_148_Global_A_IMPACT) and the German Federal Ministry of Education and Research (grant no. 01LS1711A).

Review statement. This paper was edited by Yuyu Zhou and reviewed by two anonymous referees.

\section{References}

Andres, R. J., Fielding, D. J., Marland, G., Boden, T. A., Kumar, N., and Kearney, A. T.: Carbon Dioxide Emissions from FossilFuel Use, Tellus B, 51, 759-765, https://doi.org/10.1034/j.16000889.1999.t01-3-00002.x, 1999.

Boden, T., Marland, G., and Andres, R.: Global, Regional, and National Fossil-Fuel $\mathrm{CO}_{2}$ Emissions, Carbon Dioxide Information Analysis Center (CDIAC), Oak Ridge National Laboratory (ORNL), Oak Ridge, USA, https://doi.org/10.3334/CDIAC/00001_V2017, 2017.

Bolt, J. and van Zanden, J. L.: The Maddison Project: Collaborative Research on Historical National Accounts, Econ. Hist. Rev., 67, 627-651, https://doi.org/10.1111/1468-0289.12032, 2014.

Bolt, J., Inklaar, R., de Jong, H., and van Zanden, J. L.: Maddison Project Database, Version 2018, available at: https://www.rug.nl/ggdc/historicaldevelopment/maddison/ releases/maddison-project-database-2018 (last access: 18 MArch 2019), 2018a.

Bolt, J., Inklaar, R., de Jong, H., and van Zanden, J. L.: Rebasing "Maddison": New Income Comparisons and the Shape of Long-Run Economic Development, Technical Report 10, available at: https://www.rug.nl/ggdc/html_publications/ memorandum/gd174.pdf, last access: 16 June 2018b.

Calvin, K., Bond-Lamberty, B., Clarke, L., Edmonds, J., Eom, J., Hartin, C., Kim, S., Kyle, P., Link, R., Moss, R., McJeon, H., Patel, P., Smith, S., Waldhoff, S., and Wise, M.: The SSP4: A World of Deepening Inequality, Global Environ. Chang., 42, 284-296, https://doi.org/10.1016/j.gloenvcha.2016.06.010, 2017.

Chang, C.-P. and Lee, C.-C.: Are per Capita Carbon Dioxide Emissions Converging among Industrialized Countries? New Time Series Evidence with Structural Breaks, Environ. Dev. Econ., 13, 497-515, https://doi.org/10.1017/S1355770X08004361, 2008.

Chertow, M.: The IPAT Equation and Its Variants, J. Ind. Ecol., 4, 13-29, 2000.
Climate Analytics and New Climate Institute: Climate Action Tracker, available at: https://climateactiontracker.org/, last access: 31 January 2020.

Crespo Cuaresma, J.: Income Projections for Climate Change Research: A Framework Based on Human Capital Dynamics, Global Environ. Chang., 42, 226-236, https://doi.org/10.1016/j.gloenvcha.2015.02.012, 2017.

Dellink, R., Chateau, J., Lanzi, E., and Magné, B.: LongTerm Economic Growth Projections in the Shared Socioeconomic Pathways, Global Environ. Chang., 42, 200-2014, https://doi.org/10.1016/j.gloenvcha.2015.06.004, 2017.

du Pont, Y. R., Jeffery, M. L., Gütschow, J., Christoff, P., and Meinshausen, M.: National Contributions for Decarbonizing the World Economy in Line with the G7 Agreement, Environ. Res. Lett., 11, 054005, https://doi.org/10.1088/17489326/11/5/054005, 2016.

Edenhofer, O., Pichs-Madruga, R., Sokona, Y., Farahani, E., Kadner, S., Seyboth, K., Adler, A., Baum, I., Brunner, S., Eickemeier, P., Kriemann, B., Savolainen, J., Schlömer, S., von Stechow, C., Zwickel, T., and Minx, J.: Climate Change 2014: Mitigation of Climate Change: Working Group III Contribution to the Fifth Assessment Report of the Intergovernmental Panel On Climate Change, Cambridge University Press, Cambridge, UK, available at: https://www.ipcc.ch/report/ar5/wg3/ (last access: 22 February 2016), 2014

Ehrlich, P. R. and Holdren, J. P.: Impact of Population Growth, Science, 171, 1212-1217, 1971.

Feenstra, R. C., Inklaar, R., and Timmer, M. P.: The Next Generation of the Penn World Table, Am. Econ. Rev., 105, 3150-3182, https://doi.org/10.1257/aer.20130954, 2015.

Feenstra, R. C., Inklaar, R., and Timmer, M. P.: Penn World Table Version 9.1, Am. Econ. Rev., 105, 3150-3182, https://doi.org/10.15141/S50T0R, 2019.

Feng, L., Smith, S. J., Braun, C., Crippa, M., Gidden, M. J., Hoesly, R., Klimont, Z., van Marle, M., van den Berg, M., and van der Werf, G. R.: The generation of gridded emissions data for CMIP6, Geosci. Model Dev., 13, 461-482, https://doi.org/10.5194/gmd-13-461-2020, 2020.

Fricko, O., Havlik, P., Rogelj, J., Klimont, Z., Gusti, M., Johnson, N., Kolp, P., Strubegger, M., Valin, H., Amann, M., Ermolieva, T., Forsell, N., Herrero, M., Heyes, C., Kindermann, G., Krey, V., McCollum, D. L., Obersteiner, M., Pachauri, S., Rao, S., Schmid, E., Schoepp, W., and Riahi, K.: The Marker Quantification of the Shared Socioeconomic Pathway 2: A Middle-of-the-Road Scenario for the 21st Century, Global Environ. Chang., 42, 251-267, https://doi.org/10.1016/j.gloenvcha.2016.06.004, 2017.

Fujimori, S., Hasegawa, T., Masui, T., Takahashi, K., Herran, D. S., Dai, H., Hijioka, Y., and Kainuma, M.: SSP3: AIM Implementation of Shared Socioeconomic Pathways, Global Environ. Chang., 42, 268-283, https://doi.org/10.1016/j.gloenvcha.2016.06.009, 2017.

Geiger, T.: Continuous national gross domestic product (GDP) time series for 195 countries: past observations (1850-2005) harmonized with future projections according to the Shared Socioeconomic Pathways (2006-2100), Earth Syst. Sci. Data, 10, 847856, https://doi.org/10.5194/essd-10-847-2018, 2018.

Geiger, T. and Frieler, K.: Continuous National Gross Domestic Product (GDP) Time Series for 195 Countries: Past Observations (1850-2005) Harmonized with Future Projections According the 
Shared Socio-Economic Pathways (2006-2100), GFZ Data Services, https://doi.org/10.5880/pik.2017.003, 2017.

Gidden, M. J., Riahi, K., Smith, S. J., Fujimori, S., Luderer, G., Kriegler, E., van Vuuren, D. P., van den Berg, M., Feng, L., Klein, D., Calvin, K., Doelman, J. C., Frank, S., Fricko, O., Harmsen, M., Hasegawa, T., Havlik, P., Hilaire, J., Hoesly, R., Horing, J., Popp, A., Stehfest, E., and Takahashi, K.: Global emissions pathways under different socioeconomic scenarios for use in CMIP6: a dataset of harmonized emissions trajectories through the end of the century, Geosci. Model Dev., 12, 1443 1475, https://doi.org/10.5194/gmd-12-1443-2019, 2019.

Gütschow, J.: The PRIMAP-Hist Socio-Eco Historical GDP and Population Time Series (1850-2017) (v2.1), GFZ Data Services, https://doi.org/10.5880/PIK.2019.019, 2019.

Gütschow, J., Jeffery, M. L., Gieseke, R., Gebel, R., Stevens, D., Krapp, M., and Rocha, M.: The PRIMAP-hist national historical emissions time series, Earth Syst. Sci. Data, 8, 571-603, https://doi.org/10.5194/essd-8-571-2016, 2016.

Gütschow, J., Jeffery, M. L., Gieseke, R., and Gebel, R.: The PRIMAP-Hist National Historical Emissions Time Series (1850-2015) (v1.2), GFZ Data Services, https://doi.org/10.5880/PIK.2018.003, 2018.

Gütschow, J., Jeffery, M. L., Gieseke, R., and Günther, A.: The PRIMAP-Hist National Historical Emissions Time Series (1850-2017) (v2.1), GFZ Data Services, https://doi.org/10.5880/PIK.2019.018, 2019.

Gütschow, J., Jeffery, M. L., Günther, A., and Meinshausen, M.: Country Resolved Combined Emission and Socio-Economic Pathways Based on the RCP and SSP Scenarios, Zenodo, https://doi.org/10.5281/zenodo.3638137, 2020.

Hoesly, R. M., Smith, S. J., Feng, L., Klimont, Z., JanssensMaenhout, G., Pitkanen, T., Seibert, J. J., Vu, L., Andres, R. J., Bolt, R. M., Bond, T. C., Dawidowski, L., Kholod, N., Kurokawa, J.-I., Li, M., Liu, L., Lu, Z., Moura, M. C. P., O'Rourke, P. R., and Zhang, Q.: Historical (1750-2014) anthropogenic emissions of reactive gases and aerosols from the Community Emissions Data System (CEDS), Geosci. Model Dev., 11, 369-408, https://doi.org/10.5194/gmd-11-369-2018, 2018.

Höhne, N., Blum, H., Fuglestvedt, J., Skeie, R. B., Kurosawa, A., Hu, G., Lowe, J., Gohar, L., Matthews, B., Nioac de Salles, A. C., and Ellermann, C.: Contributions of Individual Countries' Emissions to Climate Change and Their Uncertainty, Climatic Change, 106, 359-391, https://doi.org/10.1007/s10584010-9930-6, 2010.

Houghton, J. T., Meira Filho, L., Callander, B., Harris, N., Kattenberg, A., and Maskell, K.: Climate Change 1995, The Science of Climate Change, Cambridge University Press, Cambridge, UK, 1996.

IIASA: RCP Database v2.0.5, available at: https://tntcat.iiasa.ac.at/ RcpDb/ (last access: 13 March 2018), 2009.

IIASA: SSP Database (Shared Socioeconomic Pathways) Version 1.1, available at: https://tntcat.iiasa.ac.at/SspDb/ (last access: 19 June 2017), 2016.

IIASA: SSP Database (Shared Socioeconomic Pathways) Version 2.0, available at: https://tntcat.iiasa.ac.at/SspDb (last access: 14 March 2019), 2018.

Janssens-Maenhout, G., Crippa, M., Guizzardi, D., Muntean, M., Schaaf, E., Dentener, F., Bergamaschi, P., Pagliari, V., Olivier, J. G. J., Peters, J. A. H. W., van Aardenne, J. A., Monni, S., Doer- ing, U., Petrescu, A. M. R., Solazzo, E., and Oreggioni, G. D. EDGAR v4.3.2 Global Atlas of the three major greenhouse gas emissions for the period 1970-2012, Earth Syst. Sci. Data, 11, 959-1002, https://doi.org/10.5194/essd-11-959-2019, 2019.

Jewell, J. and Anderson, K.: Climate-Policy Models Debated, Nature, 573, 448-449, 2019.

Jiang, L. and O’Neill, B. C.: Global Urbanization Projections for the Shared Socioeconomic Pathways, Global Environ. Chang., 42, 192-199, https://doi.org/10.1016/j.gloenvcha.2015.03.008, 2017.

Jobert, T., Karanfil, F., and Tykhonenko, A.: Convergence of per Capita Carbon Dioxide Emissions in the EU: Legend or Reality?, Energ. Econ., 32, 1364-1373, https://doi.org/10.1016/j.eneco.2010.03.005, 2010.

JRC and PBL: Emission Database for Global Atmospheric Research Release Version 4.3.2, EDGAR, https://doi.org/10.2904/JRC_DATASET_EDGAR, 2017.

KC, S. and Lutz, W.: The Human Core of the Shared Socioeconomic Pathways: Population Scenarios by Age, Sex and Level of Education for All Countries to 2100, Global Environ. Chang., 42, 181-192, https://doi.org/10.1016/j.gloenvcha.2014.06.004, 2017.

Klein Goldewijk, C.: Anthropogenic Land-Use Estimates for the Holocene, HYDE 3.2, DANS, https://doi.org/10.17026/dans25g-gez3, 2017.

Klein Goldewijk, K., Beusen, A., Doelman, J., and Stehfest, E.: Anthropogenic land use estimates for the Holocene - HYDE 3.2, Earth Syst. Sci. Data, 9, 927-953, https://doi.org/10.5194/essd9-927-2017, 2017.

Kriegler, E., Bauer, N., Popp, A., Humpenöder, F., Leimbach, M., Strefler, J., Baumstark, L., Bodirsky, B. L., Hilaire, J., Klein, D., Mouratiadou, I., Weindl, I., Bertram, C., Dietrich, J.-P., Luderer, G., Pehl, M., Pietzcker, R., Piontek, F., Lotze-Campen, H., Biewald, A., Bonsch, M., Giannousakis, A., Kreidenweis, U., Müller, C., Rolinski, S., Schultes, A., Schwanitz, J., Stevanovic, M., Calvin, K., Emmerling, J., Fujimori, S., and Edenhofer, O.: Fossil-Fueled Development (SSP5): An Energy and Resource Intensive Scenario for the 21st Century, Global Environ. Chang., 42, 297-315, https://doi.org/10.1016/j.gloenvcha.2016.05.015, 2017.

Landman, W.: Book Review: Climate Change 2007: The Physical Science Basis, S. Afr. Geogr. J., 92, 86-87, https://doi.org/10.1080/03736245.2010.480842, 2010.

Leimbach, M., Kriegler, E., Roming, N., and Schwanitz, J.: Future Growth Patterns of World Regions - A GDP Scenario Approach, Global Environ. Chang., 42, 215-225, https://doi.org/10.1016/j.gloenvcha.2015.02.005, 2017.

Liddle, B.: Revisiting World Energy Intensity Convergence for Regional Differences, Appl. Energ., 87, 3218-3225, https://doi.org/10.1016/j.apenergy.2010.03.030, 2010.

Maddison Project: The Maddison Project 2013 Version, available at: http://www.ggdc.net/maddison/maddison-project/home htm (last access: 16 June 2017), 2013.

Markandya, A., Pedroso-Galinato, S., and Streimikiene, D.: Energy Intensity in Transition Economies: Is There Convergence towards the EU Average?, Energ. Econ., 28, 121-145, https://doi.org/10.1016/j.eneco.2005.10.005, 2006.

Marland, G. and Rotty, R. M.: Carbon Dioxide Emissions from Fossil Fuels: A Procedure for Estimation and Results for 1950 
1982, Tellus B, 36, 232-261, https://doi.org/10.1111/j.16000889.1984.tb00245.x, 1984.

Masui, T., Matsumoto, K., Hijioka, Y., Kinoshita, T., Nozawa, T., Ishiwatari, S., Kato, E., Shukla, P. R., Yamagata, Y., and Kainuma, M.: An Emission Pathway for Stabilization at $6 \mathrm{Wm}^{-2}$ Radiative Forcing, Climatic Change, 109, 59-76, https://doi.org/10.1007/s10584-011-0150-5, 2011.

Meinshausen, M., Smith, S. J., Calvin, K., Daniel, J. S., Kainuma, M. L. T., Lamarque, J.-F., Matsumoto, K., Montzka, S., Raper, S. C. B., Riahi, K., Thomson, A., Velders, G. J. M., and Vuuren, D. P.: The RCP Greenhouse Gas Concentrations and Their Extensions from 1765 to 2300, Climatic Change, 109, 213-241, https://doi.org/10.1007/s10584-011-0156-z, 2011.

Meinshausen, M., Jeffery, L., Guetschow, J., Robiou du Pont, Y., Rogelj, J., Schaeffer, M., Höhne, N., den Elzen, M., Oberthür, S., and Meinshausen, N.: National Post-2020 Greenhouse Gas Targets and Diversity-Aware Leadership, Nat. Clim. Change, 5, 1098-1106, https://doi.org/10.1038/nclimate2826, 2015.

Meinshausen, M., Vogel, E., Nauels, A., Lorbacher, K., Meinshausen, N., Etheridge, D. M., Fraser, P. J., Montzka, S. A., Rayner, P. J., Trudinger, C. M., Krummel, P. B., Beyerle, U., Canadell, J. G., Daniel, J. S., Enting, I. G., Law, R. M., Lunder, C. R., O’Doherty, S., Prinn, R. G., Reimann, S., Rubino, M., Velders, G. J. M., Vollmer, M. K., Wang, R. H. J., and Weiss, R.: Historical greenhouse gas concentrations for climate modelling (CMIP6), Geosci. Model Dev., 10, 2057-2116, https://doi.org/10.5194/gmd-10-2057-2017, 2017.

Moss, R. H., Edmonds, J., Hibbard, K., Manning, M. R., Rose, S. K., van Vuuren, D. P., Carter, T. R., Emori, S., Kainuma, M., Kram, T., Meehl, G., Mitchell, J. F. B., Nakicenovic, N., Riahi, K., Smith, S. J., Stouffer, R. J., Thomson, A. M., Weyant, J. P., and Wilbanks, T. J.: The next Generation of Scenarios for Climate Change Research and Assessment, Nature, 463, 747-56, https://doi.org/10.1038/nature08823, 2010.

Nakicenovic, N. and Swart, R.: Special Report on Emissions Scenarios: A Special Report of Working Group III of the Intergovernmental Panel on Climate Change, Cambridge University Press, Cambridge, UK, 2000.

Nakicenovic, N., Alcamo, J., Davis, G., de Vries, B., Fenhann, J., Gaffin, S., Gregory, K., Grübler, A., Yong Jung, T., Kram, T., La Rovere, E. L., Michaelis, L., Mori, S., Morita, T., Pepper, W., Pitcher, H., Price, L., Riahi, K., Roehrl, A., Rogner, H.-H., Sankovski, A., Schlesinger, M., Shukla, P., Smith, S., Swart, R., van Rooijen, S., Victor, N., and Dadi, Z.: Emissions Scenarios, Special Report of Working Group III of the Intergovernmental Panel on Climate Change, Cambridge University Press, Cambridge, UK, 2000.

Nakicenovic, N., Lempert, R. J., and Janetos, A. C.: A Framework for the Development of New Socio-Economic Scenarios for Climate Change Research: Introductory Essay, Climatic Change, 122, 351-361, https://doi.org/10.1007/s10584013-0982-2, 2014.

Ordás Criado, C. and Grether, J.-M.: Convergence in per Capita $\mathrm{CO}_{2}$ Emissions: A Robust Distributional Approach, Resour. Energy Econ., 33, 637-665, https://doi.org/10.1016/j.reseneeco.2011.01.003, 2011.

Owen, B., Lee, D. S., and Lim, L.: Flying into the Future: Aviation Emissions Scenarios to 2050, Environ. Sci. Technol., 44, 22552260, https://doi.org/10.1021/es902530z, 2010.
Panopoulou, E. and Pantelidis, T.: Club Convergence in Carbon Dioxide Emissions, Environ. Resour. Econ., 44, 47-70, https://doi.org/10.1007/s10640-008-9260-6, 2009.

Peters, G. P., Andrew, R. M., Canadell, J. G., Fuss, S., Jackson, R. B., Korsbakken, J. I., Le Quéré, C., and Nakicenovic, N.: Key Indicators to Track Current Progress and Future Ambition of the Paris Agreement, Nat. Clim. Change, 7, 118-122, https://doi.org/10.1038/nclimate3202, 2017.

PRIMAP: Paris Reality Check, available at: https://www. pik-potsdam.de/paris-reality-check/ (last access: 2 January 2020), 2020.

QUANTIFY: QUANTIFY Project Website, available at: https:// www.pa.op.dlr.de/quantify/ (last access: 5 February 2017), 2010.

Riahi, K., Grübler, A., and Nakicenovic, N.: Scenarios of LongTerm Socio-Economic and Environmental Development under Climate Stabilization, Technol. Forecast. Soc., 74, 887-935, https://doi.org/10.1016/j.techfore.2006.05.026, 2007.

Riahi, K., Rao, S., Krey, V., Cho, C., Chirkov, V., Fischer, G., Kindermann, G., Nakicenovic, N., and Rafaj, P.: RCP 8.5 - A Scenario of Comparatively High Greenhouse Gas Emissions, Climatic Change, 109, 33-57, https://doi.org/10.1007/s10584-0110149-y, 2011.

Riahi, K., van Vuuren, D., Kriegler, E., Edmonds, J., O’Neill, B., Fujimori, S., Bauer, N., Calvin, K., Dellink, R., Fricko, O., Lutz, W., Popp, A., Cuaresma, C. J., Samir, K., Leimback, M., Jiang, L., Kram, T., Rao, S., Emmerling, J., Ebi, K., Hasegawa, T., Havlik, P., Humpenöder, F., Da Silva, L., Smith, S., Stehfest, E., Bosetti, V., Eom, J., Gernaat, D., Masui, T., Rogelj, J., Strefler, J., Drouet, L., Krey, V., Luderer, G., Harmsen, M., Takahashi, K., Baumstark, L., Doelman, J., Kainuma, M., Klimont, Z., Marangoni, G., Lotze-Campen, H., Obersteiner, M., Tabeau, A., and Tavoni, M.: The Shared Socioeconomic Pathways and Their Energy, Land Use, and Greenhouse Gas Emissions Implications: An Overview, Global Environ. Chang., 42, 153-168, https://doi.org/10.1016/j.gloenvcha.2016.05.009, 2017.

Robiou du Pont, Y. and Meinshausen, M.: Warming Assessment of the Bottom-up Paris Agreement Emissions Pledges, Nat. Commun., 9, 4810, https://doi.org/10.1038/s41467-018-072239, 2018

Robiou du Pont, Y., Jeffery, M. L., Gütschow, J., Rogelj, J., Christoff, P., and Meinshausen, M.: Equitable Mitigation to Achieve the Paris Agreement Goals, Nat. Clim. Change, 7, 38 43, https://doi.org/10.1038/nclimate3186, 2016.

Rogelj, J., Popp, A., Calvin, K. V., Luderer, G., Emmerling, J., Gernaat, D., Fujimori, S., Strefler, J., Hasegawa, T., Marangoni, G., Krey, V., Kriegler, E., Riahi, K., van Vuuren, D. P., Doelman, J., Drouet, L., Edmonds, J., Fricko, O., Harmsen, M., Havlík, P., Humpenöder, F., Stehfest, E., and Tavoni, M.: Scenarios towards Limiting Global Mean Temperature Increase below $1.5^{\circ} \mathrm{C}$, Nat. Clim. Change, 8, 325-332, https://doi.org/10.1038/s41558-0180091-3, 2018.

Romero-Ávila, D.: Convergence in Carbon Dioxide Emissions among Industrialised Countries Revisited, Energ. Econ., 30, 2265-2282, https://doi.org/10.1016/j.eneco.2007.06.003, 2008.

Smith, T., Jalkanen, J., Anderson, B., Corbett, J., Faber, J., Hanayama, S., O’Keeffe, E., Parker, S., Johansson, L., Aldous, L., Raucci, C., Traut, M., Ettinger, S., Nelissen, D., Lee, D., Ng, S., Agrawal, A., Winebrake, J., Hoen, M., and Pandey, A.: Third IMO GHG Study 2014: Ex- 
ecutive Summary and Final Report, International Maritime Organization, available at: http://www.imo.org/en/ OurWork/Environment/PollutionPrevention/AirPollution/ Documents/Third\%20Greenhouse\%20Gas\%20Study/GHG3\% 20Executive\%20Summary\%20and\%20Report.pdf (last access: 21 January 2020), 2014.

SSP: SSP Model Documentation, available at: https: //tntcat.iiasa.ac.at/SspDb/download/iam_scenario_doc/SSP_ Model_Documentation.pdf (last access: 9 January 2020), 2015.

Stegman, A. and McKibbin, W. J.: Convergence and per Capita Carbon Emissions, Brookings Discussion Papers in International Economics, available at: https://www.brookings.edu/research/ convergence-and-per-capita-carbon-emissions/ (last access: 8 August 2013), 2005.

Strazicich, M. and List, J.: Are $\mathrm{CO}_{2}$ Emission Levels Converging among Industrial Countries?, Environ. Resour. Econ., 24, 263271, https://doi.org/10.1023/A:1022910701857, 2003.

The World Bank: Global Purchasing Power Parities and Real Expenditures - 2005 International Comparison Program, The World Bank, available at: http://pubdocs.worldbank.org/en/ 982121487105148964/2005ICPReport-FinalwithNewAppG.pdf (last access: 13 January 2020), 2008.

The World Bank: Purchasing Power Parities and the Real Size of World Economies: A Comprehensive Report of the 2011 International Comparison Program, The World Bank, available at: https://elibrary.worldbank.org/doi/abs/10. 1596/978-1-4648-0329-1 (last access: 13 January 2020), 2014.

The World Bank: World Development Indicators July 2019, available at: https://datacatalog.worldbank.org/dataset/ world-development-indicators, last access: 22 July 2019a.

The World Bank: World Development Indicators, available at: http: //datatopics.worldbank.org/world-development-indicators/, last access: 28 March 2019b.

Thomson, A. M., Calvin, K. V., Smith, S. J., Kyle, G. P., Volke, A., Patel, P., Delgado-Arias, S., Bond-Lamberty, B., Wise, M., Clarke, L. E., and Edmonds, J.: RCP4.5: A Pathway for Stabilization of Radiative Forcing by 2100, Climatic Change, 109, 77-94, https://doi.org/10.1007/s10584-011-0151-4, 2011.

UN DESA/Population Division: World Population Prospects 2019, available at: https://esa.un.org/unpd/wpp/, last access: 1 June 2019. van Vuuren, D. P., Lucas, P. L., and Hilderink, H. B. M.: Downscaling Drivers of Global Environmental Change, Technical Report, Netherlands Environmental Assessment Agency, available at: https://www.pbl.nl/en/publications/ DownscalingDriversOfGlobalEnvironmentalChangeScenarios (last access: 17 October 2012), 2006.

van Vuuren, D. P., Lucas, P. L., and Hilderink, H.: Downscaling Drivers of Global Environmental Change: Enabling Use of Global SRES Scenarios at the National and Grid Levels, Global Environ. Chang., 17, 114-130, https://doi.org/10.1016/j.gloenvcha.2006.04.004, 2007.

van Vuuren, D. P., Edmonds, J., Kainuma, M., Riahi, K., Thomson, A., Hibbard, K., Hurtt, G. C., Kram, T., Krey, V., Lamarque, J. F., Masui, T., Meinshausen, M., Nakicenovic, N., Smith, S. J., and Rose, S. K.: The Representative Concentration Pathways: An Overview, Climatic Change, 109, 5-31, https://doi.org/10.1007/s10584-011-0148-z, 2011a.

van Vuuren, D. P., Stehfest, E., Elzen, M. G. J., Kram, T., Vliet, J., Deetman, S., Isaac, M., Klein Goldewijk, K., Hof, A., Mendoza Beltran, A., Oostenrijk, R., and Ruijven, B.: RCP2.6: Exploring the Possibility to Keep Global Mean Temperature Increase below $2^{\circ} \mathrm{C}$, Climatic Change, 109, 95-116, https://doi.org/10.1007/s10584-011-0152-3, $2011 \mathrm{~b}$.

van Vuuren, D. P., Kriegler, E., O’Neill, B. C., Ebi, K. L., Riahi, K., Carter, T. R., Edmonds, J., Hallegatte, S., Kram, T., Mathur, R., and Winkler, H.: A New Scenario Framework for Climate Change Research: Scenario Matrix Architecture, Climatic Change, 122, 373-386, https://doi.org/10.1007/s10584013-0906-1, 2014.

van Vuuren, D. P., Stehfest, E., Gernaat, D. E. H. J., Doelman, J. C., van den Berg, M., Harmsen, M., de Boer, H. S., Bouwman, L. F., Daioglou, V., Edelenbosch, O. Y., Girod, B., Kram, T., Lassaletta, L., Lucas, P. L., van Meijl, H., Müller, C., van Ruijven, B. J., van der Sluis, S., and Tabeau, A.: Energy, Land-Use and Greenhouse Gas Emissions Trajectories under a Green Growth Paradigm, Global Environ. Chang., 42, 237-250, https://doi.org/10.1016/j.gloenvcha.2016.05.008, 2017.

World Climate Research Programme: CMIP Phase 6 (CMIP6), available at: https://www.wcrp-climate.org/wgcm-cmip/ wgcm-cmip6, last access: 14 March 2019. 